\title{
An ERA40-based atmospheric forcing for global ocean circulation models
}

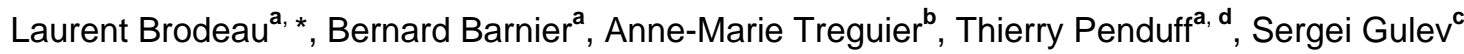 \\ a LEGI, UMR 5519 CNRS-UJF-INPG, BP 53, 38041 Grenoble, France \\ ${ }^{\mathrm{b}}$ LPO, UMR 6523 CNRS-IFREMER-IRD-UBO, IFREMER, BP 70, 29280 Plouzané, France \\ c P.P. SIO - RAS, 36 Nakhimovsky Ave., 117218 Moscow, Russian Federation \\ ${ }^{d}$ Department of Oceanography, The Florida State University, Tallahassee, Florida \\ *: Corresponding author : Laurent Brodeau, email address : laurent@misu.su.se ; brodeau@gmail.com
}

\begin{abstract}
:
We develop, calibrate and test a dataset intended to drive global ocean hindcasts simulations of the last five decades. This dataset provides surface meteorological variables needed to estimate air-sea fluxes and is built from 6-hourly surface atmospheric state variables of ERA40. We first compare the raw fields of ERA40 to the CORE.v1 dataset of Large and Yeager (2004), used here as a reference, and discuss our choice to use daily radiative fluxes and monthly precipitation products extracted from satellite data rather than their ERA40 counterparts. Both datasets lead to excessively high global imbalances of heat and freshwater fluxes when tested with a prescribed climatological sea surface temperature. After identifying unrealistic time discontinuities (induced by changes in the nature of assimilated observations) and obvious global and regional biases in ERA40 fields (by comparison to high quality observations), we propose a set of corrections. Tropical surface air humidity is decreased from 1979 onward, representation of Arctic surface air temperature is improved using recent observations and the wind is globally increased. These corrections lead to a significant decrease of the excessive positive global imbalance of heat. Radiation and precipitation fields are then submitted to a small adjustment (in zonal mean) that yields a near-zero global imbalance of heat and freshwater. A set of 47-year-long simulations is carried out with the coarse-resolution $\left(2^{\circ} \times 2^{\circ}\right)$ version of the NEMO OGCM to assess the sensitivity of the model to the proposed corrections. Model results show that each of the proposed correction contributes to improve the representation of central features of the global ocean circulation.
\end{abstract}

Keywords : Ocean ; Hindcast ; Atmospheric forcing ; Air-sea fluxes ; Weather reanalyzes ; Satellite

\section{Introduction}

Simulating the evolution of the global ocean over the last few decades using Ocean General Circulation models (OGCMs) has been made possible since globally gridded interannual weather reanalysis products have become available. Atmospheric fields from these reanalyzes are used to derive fluxes to be applied as surface boundary conditions for OGCMs. Large and Yeager (2004), hereafter referred to as LY04, introduced a dataset for the "Coordinated Ocean Reference Experiments" carried out in the framework of the Working Group on Ocean Model Development (WGOMD) of WCRP (COREs, Griffies et al., 2009). This dataset 
provides the ocean modeling community with a complete long-term ocean and sea-ice forcing, intended to drive interannual OGCM inter-comparisons and ocean hindcast experiments of the last 5 decades (1958 to present). This dataset, from now on referred to as LYDS (Large and Yeager Data Set), is based on the NCEP reanalysis (Kalnay et al., 1996) and implements recent reconstructed flux products as a replacement for traditionally weak components of reanalyzes, such as radiation and precipitation (Table 1). The authors applied corrections to these original fields and they verified that corrections are consistent with a near-zero global imbalance of heat and freshwater fluxes estimated from a prescribed sea surface temperature (SST) and seaice concentration. LYDS will serve as our reference dataset when building our ERA40-based datasets.

Röske (2006) developed another dataset designed to force ocean models based on ERA15, the first reanalysis carried out at ECMWF (Gibson et al., 1997). He applied corrections to close heat and freshwater budgets by means of an inverse procedure. However, only a climatological year was estimated due to the short time coverage of ERA15 (1979-1993).

Ocean forcing datasets such as those discussed here must be continuously reevaluated and updated to account for new observations (especially from satellites), new atmospheric reanalyzes, and feedbacks from the modeling community. This has been done recently for LYDS, in coordination with WGOMD, and a new release has been recently made available (Large and Yeager, 2008) which is sometimes referred to as CORE.v2.

Being more recent than NCEP or ERA15, the ERA40 reanalysis of ECMWF (Uppala et al., 2005) takes advantage of more advanced numerical features (such as resolution, atmospheric models and assimilation schemes), and is therefore regarded as a second generation reanalysis. This paper is an attempt to implement ERA40 fields into a dataset intended to drive multidecadal hindcasts of the ocean of the period 1958 to present. The authors are part of the DRAKKAR group (The DRAKKAR Group, 2007) who develops a hierarchy of ice-ocean models based on the NEMO code (Madec, 2008). This hierarchy comprises Global and North Atlantic model configurations, at resolutions varying from coarse $\left(2^{\circ}, 1^{\circ}, 1 / 2^{\circ}\right)$ to eddy-permitting or resolving $\left(1 / 4^{\circ}, 1 / 12^{\circ}\right)$, and is used to investigate open questions related to the variability of the ocean circulation and water mass properties during past decades, and their effects on climate through the transport of heat. In this paper, the sensitivity of the coarse-resolution $\left(2^{\circ}\right)$ model configuration to the forcing parameters is investigated, after Brodeau (2007) has shown that it provides intuition about the response of the eddy-resolving models to the forcing. The same sensitivity tests are much to costly (computationally) to be performed at $1 / 4^{\circ}$ or $1 / 12^{\circ}$ resolution. We emphasize that our choice of corrections to ERA40 variables is not driven by model results: flaws or discontinuities have been confirmed by comparison with observations or other flux related products.

In Section 2, we review both theoretical and practical aspects of the bulk forcing method chosen to estimate air-sea fluxes, we also present the prescribed SST offline approach used to check on heat and freshwater budget of each dataset to be evaluated. In Section 3, after briefly describing the Large and Yeager dataset that we use here as reference, we focus on ERA40 atmospheric fields and their ability to stand as relevant candidates for forcing an OGCM. In Section 4 we propose different corrections to apply on each field of our original-ERA40-based dataset. These corrections are guided by comparisons with recent observations or analysis products and the constraint to minimize the imbalance of heat and freshwater of the global ocean, in the spirit of LY04. Unfortunately, ECMWF (and other NWP centers) do not provide uncertainties for their 
reanalysis fields. Therefore, there is no uncertainty estimate available for ERA40 variables. Few authors in search for estimates of these uncertainties have considered differences between NCEP and ERA40 as indicators (e.g. Lucas et al., 2008 or Leeuwenburgh, 2005 their approach, limited to smaller regions and short periods, was justified by very specific objectives, such as stochastic analysis of model errors or data assimilation. In the present study, we did not search for a method that could provide quantitative uncertainty estimates to the forcing fields resulting from our analyzes. In the future, it is clear that progresses in ocean model development and ocean forecasting will be greatly facilitated if error estimates were provided in atmospheric reanalyzes and downstream forcing products. As a final validating step, Section 5 discusses results from global interannual simulations carried out with a numerical ocean/sea-ice circulation model driven by every atmospheric dataset previously produced. Section 6 closes the paper with a summary of the main results and conclusions.

\section{Bulk air-sea fluxes}

OGCMs traditionally need to be given surface fluxes of momentum (i.e. wind stress), heat and freshwater as surface boundary conditions for the equations of conservation for momentum, heat, salt and water volume for models with explicit freshwater fluxes. We choose the bulk forcing approach discussed by Large et al. (1997) to estimate surface fluxes, and the bulk formulae used are those extensively described in Large and Yeager (2004).

Turbulent fluxes such as wind stress $(\vec{\tau})$, sensible heat flux $\left(Q_{\text {sens }}\right)$ and evaporation $(E)$ are estimated from Surface Atmospheric State variables (SAS) and sea surface temperature (SST) using a parameterization known as bulk aerodynamic formulae. SAS variables involved are the surface wind vector $\vec{U}_{10}$, air surface temperature $\theta_{\text {air }}$ and surface specific humidity $q_{\text {air }}$. While the wind is generally provided at the reference height of $10 \mathrm{~m}$, air temperature and humidity reference height can vary depending on the origin of the data ( $2 \mathrm{~m}$ in ERA40). The radiative shortwave and longwave components of the surface net heat flux $\left(Q_{s w}\right.$ and $\left.Q_{l w}\right)$ are estimated from the daily downwelling shortwave and longwave radiation available at the sea level, noted $\mathrm{rad}_{s w}$ and $\mathrm{rad}_{l w}$. Surface albedo is needed to estimate $Q_{s w}$ as the fraction of $\operatorname{rad}_{s w}$ absorbed by the ocean; a constant sea surface albedo, $\alpha=0.066$, is used in all flux calculations made here, whether an observed or a model SST is used. SST is required to estimate the upward longwave flux emitted by the sea which is needed to determine $Q_{l w}$.

The net surface freshwater flux is calculated as the sum of precipitation and continental runoff minus evaporation: $F_{W}=P+R-E$. The latent heat flux $Q_{l a t}$ is deduced from the evaporation term $E$ and the latent heat of vaporization of water $L_{v a p}: Q_{l a t}=L_{v a p} E$, with $L_{v a p}=(2.501-$ $0.00237 S S T) 10^{6} \mathrm{~J} / \mathrm{kg}$, where $Q_{\text {lat }}$ is in $\mathrm{W} / \mathrm{m}^{2}, E$ is in $\mathrm{kg} / \mathrm{m}^{2} / \mathrm{s}$, and the SST is given in ${ }^{\circ} \mathrm{C}$. The dependence of $L_{v a p}$ on SST is indeed not negligible as $L_{v a p}$ is $\simeq 2.510^{6} \mathrm{~J} / \mathrm{kg}$ at a temperature of $0^{\circ} \mathrm{C}$ and $L_{v a p}$ is $\simeq 2.4310^{6} \mathrm{~J} / \mathrm{kg}$ at a temperature of $30^{\circ} \mathrm{C}$. Using a constant value of $L_{v a p}$ of $2.510^{6} \mathrm{~J} / \mathrm{kg}$ as it is done in many model simulations overestimate the latent heat loss by $3 \%$ in the tropical band, leading to a deficit of heat input of about $4 \mathrm{~W} / \mathrm{m}^{2}$.

Whether they are used to build flux climatologies from a prescribed SST or to drive the NEMO OGCM, surface fluxes are calculated following the exact same way described above in the present study. We follow the recommendations of Large et al. (1997) for the frequency of atmospheric variables, which must be high enough for turbulent fluxes due to the high nonlinearity of the bulk formulae. Wind stress, latent and sensible heat fluxes and evaporation are 
therefore calculated every 6-hours using 6-hourly SAS fields. Both components of the radiative heat flux are computed daily using the longwave and shortwave components of the downwelling radiation, a fixed surface albedo and the SST. When fluxes are calculated with a prescribed SST, we use a monthly interannual climatology. For ocean simulation, the SST calculated by the model at the current time step is used.

The global monthly climatology of continental runoff is the same as used by Timmermann et al. (2005). It is based on the seasonal cycle of the flow rate in the main rivers, derived from the Global Runoff Data Centre (2000) data, and a climatology of the coastal runoff of smaller rivers based on Baumgartner and Reichel (1975). To represent ice calving of Antarctica, a flux of 0.082 Sv estimated from Jacobs and Comiso (1989) is added over the Southern Ocean south of $55^{\circ} \mathrm{S}$. The total annual mean runoff is $1.29 \mathrm{~Sv}$. It is somehow increased (by a global factor) to reach an annual value of $1.3 \mathrm{~Sv}$. It is an acceptable value as many authors report values equal or superior to $1.3 \mathrm{~Sv}$ (Fekete et al., 2000; Oki, 1999). Our choice is mainly justified by the need to provide a consistent response to the increase of evaporation induced by the wind correction of our final dataset.

In the following, observed monthly interannual SST and sea-ice concentration climatologies of Hurrell et al. (2008) are used to estimate air-sea fluxes from a given set of atmospheric variables and bulk parameterization. This approach is widely used by the climate community for building flux climatologies and to adjust atmospheric fields or bulk formulae. Flux calculations are carried out from 1958 to 2004 on the global ORCA2 grid that is also used for the ocean model simulations presented in Section 5, Our calculation ends in 2004 as dictated by the availability of the LYDS fields at the beginning of our study. SST and sea-ice concentration are linearly interpolated from monthly to daily values. Following the method described by LY04, turbulent fluxes are computed every 6 hours. Daily-averaged turbulent heat fluxes and daily radiation input provide the daily net heat flux estimate while monthly-averaged evaporation plus monthly precipitation and runoff provide the monthly net freshwater flux estimate.

\section{DFS3: a forcing dataset based on ERA40}

In this section, we review the atmospheric fields used by LY04 to build their dataset (LYDS). We assess the ability of the corresponding ERA40 fields to stand as relevant candidates to drive ocean-ice models by comparing them to LYDS and third party data. The global balance of heat and freshwater induced by LYDS and our first ERA40-based dataset, named DFS3 for DRAKKAR Forcing Set \#3, is studied for the 1958-2004 period.

\subsection{Reanalysis fluxes versus satellite products}

\subsubsection{Radiation}

LY04 did not use NCEP radiation and precipitation in their dataset. Both precipitation and downwelling radiation estimates heavily depend on the representation of the cloud cover, which is one of the weakest feature of weather forecasting models (Taylor, 2000). Instead, they favored the use of the ISCCP-FD radiation product developed by Zhang et al. (2004). These fields are outputs of the radiative transfer model of the NASA Goddard Institute for Space Studies (GISS) and are based on various satellite data and climatologies gathered by the ISCCP. However, these fields are not in a form that makes them directly usable to drive an ocean model. A significant 
amount of processing was made by LY04 to produce regular gridded daily fields for the period 1984 to 2004. LY04 also reduced the downwelling shortwave radiation of the original product by $5 \%$ between $50^{\circ} \mathrm{S}$ and $40^{\circ} \mathrm{N}$ to better agree with other independent products. The effect of this correction can be seen in Fig. 11a which displays the zonal average downward shortwave radiations for different datasets (compare ISCCP-FD to LYDS). Despite the correction, LYDS shortwave radiation remains high, greater than the NOC climatology for example. They also limited arctic shortwave input by applying a negative offset of $5 \mathrm{~W} / \mathrm{m}^{2}$ north to $70^{\circ} \mathrm{N}$. In LYDS, a climatological daily mean of radiation fields, built as the average of years 1984 to 2004, is used to cover the missing years (1958 to 1983).

ECMWF documentation is clear on that matter, the quality of ERA40 radiative products is not satisfactory. Quoting their website1: "Radiation budget fields suffer from deficiencies in the radiative properties of the clouds, and are not recommended for use in studies where accurate fluxes are required." This is confirmed when comparing ISCCP and ERA40 interannual variability of the zonally-averaged downwelling shortwave radiation between 1984 and 2000 (Fig.2). ERA40 exhibits an unrealistic variability pattern when compared to the ISCCP-FD dataset, the time variability of the latter being considered more reliable as it is based on satellite observations. A substantial underestimation of the tropical insolation is introduced in ERA40 from 1991 onwards. This problem is likely to be linked to the well-documented issue of an overestimation of tropical precipitation in ERA40: the eruption of Mt. Pinatubo in 1991 is reported to have introduced a misinterpretation of the HIRS infrared radiance data by the assimilation scheme, due to the effects of volcanic aerosols (Uppala et al., 2004). The result is a significant increase of ERA40 rainfall over the tropical oceans during the last years (see next paragraph). The resulting tropical underestimation of shortwave radiation in ERA40 is striking when looking at zonally-averaged radiation from different origins displayed in Fig.11a.

Another important discrepancy between data from ISCCP and ERA40 is found along the west coasts of continents between roughly $20^{\circ}$ and $30^{\circ}$ latitude in both hemispheres (no figure shown). In these regions, ERA40 can locally overestimate the annual mean insolation by more than $60 \mathrm{~W} / \mathrm{m}^{2}$. This flaw, linked to the ECMWF prognostic cloud model, is a recurrent flaw in ECMWF products, already discussed by Gibson et al. (1997). It is due to a poor representation of low-level stratus and stratocumulus in the regions of subsidence of the Walker cell.

\subsubsection{Precipitation}

LY04 reviewed and compared precipitation data from different sources and then developed a global precipitation dataset, named GXGXS, based on a zonal blending of several products, including two of the most widely used datasets: GPCP (Huffman et al.. 1997) and CMAP (Xie and Arkin, 1997). A third party data source, the Serreze and Hurst (2000) dataset was used to cover the Arctic region. All these datasets (excepted for Serreze, which is a climatology) are currently available starting from 1979. LY04 also applied a global correction on the GXGXS precipitations which increases precipitation everywhere: $P_{L Y D S}=1.1417 P_{G X G X S}+0.7$ (in $10^{-6} \mathrm{mg} / \mathrm{s} / \mathrm{m}^{2}$ ). The effect of this correction is illustrated in Fig. $1 \mathrm{~b}$ (compare GXGXS and LYDS).

\footnotetext{
${ }^{1}$ http://www.ecmwf.int/research/era/Data_Services/section3.html
} 
Troccoli and Kållberg (2004), describe the excessive tropical precipitation as "the most serious drawback of the ERA40 reanalysis". This excess of precipitation is the result of two previously discussed flaws of the ECMWF model: the "satellite-moistened" tropical air and the sequel of the Mt. Pinatubo disturbance. They propose a tropical correction to the original ERA40 rainfall. The resulting precipitation field (ERA40-TK) is compared to other precipitation fields in Fig. 1 b. Despite the correction, ERA40-TK precipitation remains high compared to GXGXS (i.e. GPCP or CMAP) in the tropical band and tends to be lower over mid latitude oceans. Such a bias was already noticed by Béranger et al. (2006) in the first ECMWF reanalysis ERA15. The comparison was not conducted in further details as it is clear that the GXGXS stands as a more reliable product.

These considerations led us to avoid using ERA40 radiation and precipitation, and to follow LY04 in using satellite products for radiation and precipitation.

\subsection{Surface atmospheric state variables}

We consider here the use of ERA40 (1958-2001) and ECMWF Operational Analysis (hereafter EOA, from 2002 to 2007) for building series of SAS fields of the DFS3, beginning in 1958 and extending to 2007. Potential time-discontinuities at the 2001-2002 transition between ERA40 and EOA are discussed and treated while constructing the DRAKKAR Forcing Set \#4 (DFS4) in Section 4. For relevant comparison between LYDS and DFS3, 2m variables of ERA40 such as air temperature and specific humidity are adjusted to $10 \mathrm{~m}$ using 6-hourly SST and wind fields of ERA40 and the same Monin-Obukhov similarity theory parameterization used by LY04 to adjust NCEP variables to $10 \mathrm{~m}$. Note that if the time series of the atmospheric surface variables are extended up to 2007 with the EOA (as it can be seen in several figures), the comparison with LYDS and the simulations with the ORCA2 model are stopped in 2004.

\subsubsection{Surface wind}

When estimated with bulk formulae, all turbulent heat fluxes are proportional to the wind module. Fig. 3a displays the zonal average wind speed for different datasets used in this study. LYDS winds are greater than NCEP winds by roughly $1 \mathrm{~m} / \mathrm{s}$. The meridional structures of zonally-averaged NCEP and ERA40 winds are in a good qualitative agreement with QuikSCAT, which however exhibits much stronger values (Fig. 3a). ERA40 winds are generally weaker than NCEP except at the Equator and south of the ACC. This suggests that ERA40 globally underestimates the wind speed, even though QuikSCAT may be victim of problematic overestimations in Equatorial regions as discussed in Section 4.2 .

\subsubsection{Surface air humidity}

The zonal average of the corrected LYDS air humidity is compared to ERA40 in Fig. 3b. It shows that ERA40 air is dryer at high and mid-latitudes, and moister in the equatorial band. Excessive tropical humidity is a known flaw of ERA40. Andersson et al. (2005) report that a moist bias was introduced over tropical oceans due to the assimilation of satellite data. Outside the tropical oceans, surface air in ERA40 is significantly dryer than in LYDS (of the order of $-0.5 \mathrm{~g} / \mathrm{kg}$ ) (Fig. 3b). This is particularly true in the southern hemisphere where the disagreement reaches $0.75 \mathrm{~g} / \mathrm{kg}$ at $25^{\circ} \mathrm{S}$. At high latitudes, where cold air constrains very low values of specific humidity, the difference between the two datasets is negligible. 


\subsubsection{Surface air temperature}

LY04 applied corrections to NCEP air temperature at in high latitudes. A seasonal correction is applied in the Arctic (north of $70^{\circ} \mathrm{N}$ ) to better fit in-situ data of the POLES project (Rigor et al., 2000), and a cold bias, related to extreme southern latitudes south to $60^{\circ} \mathrm{S}$ is also removed in order to avoid unrealistically low temperatures in the vicinity of Antarctica. The zonal average of the corrected LYDS air temperature is compared to ERA40 in Fig. 3b. ERA40 is warmer in the inter-tropical band and in polar regions, and colder in mid and high latitudes.

Agreement between LYDS and ERA40 surface air temperature is excellent in terms of interannual variability (no figure shown). Comparison of zonal averages (Fig.3b) shows that except at high latitudes regions, the mismatch between the two datasets never exceeds a few tenth of a degree, ERA40 air being warmer under low latitudes and cooler at mid latitudes. Regions of oceanic deep convection in the North Atlantic (i.e. the latitude band between $60^{\circ}$ and $70^{\circ} \mathrm{N}$ ) show a $1^{\circ}$ drop of ERA40 mean temperature relative to LYDS. ERA40 air is warmer in polar regions of both hemispheres, especially in the north where the temperature is about $1{ }^{\circ} \mathrm{C}$ greater. This is particularly marked in winter over ice where ERA40 locally shows seasonal excess of temperature up to $5^{\circ} \mathrm{C}$ as illustrated in Fig. 4 b by the temperature difference between the two datasets. However, in ice-free regions of the Arctic, ERA40 gives colder temperatures in winter. The colder and drier ERA40 air in these regions is therefore expected to increase buoyancy loss and enhance oceanic deep convection. In summer in the Arctic (Fig.4d), ERA40 air temperature remains significantly warmer but differences between the datasets are generally twice as small as in winter. The area surrounding southern Greenland seems to be the only region where air in ERA40 remains much colder than in LYDS.

\subsubsection{DFS3 dataset}

The DFS3 dataset is finally defined as the forcing set based on un-corrected surface atmospheric state variables of ERA40 extended in time until 2007 with fields of the ECMWF operational analysis, and the radiation and precipitation products proposed by Large and Yeager (2004) (see Table 1). As for LYDS, the seasonal climatology is used for radiation fluxes before 1984 (and before 1979 for precipitation), and interannually varying monthly mean fields are used afterward (Table1).

\subsection{Global balance of DFS3}

When computing net heat and freshwater fluxes for the 1958-2004 period with the prescribed SST method, LYDS and DFS3 datasets lead to a similar excess of heat for the ocean, an imbalance of the order of $+10 \mathrm{~W} / \mathrm{m}^{2}\left(10.4\right.$ and $12.8 \mathrm{~W} / \mathrm{m}^{2}$ respectively, Table 2). Regarding the freshwater flux, the two datasets lead to a rise of the globally-averaged sea level of respectively 25 and $56 \mathrm{~mm} /$ year. These unrealistically high values do not seem to be consistent with the near-zero imbalance of heat and freshwater of LYDS reported by Large and Yeager (2004). However, the following differences in our approach must be noted. In LY04, net heat and fresh water fluxes were affected by a bug in the Fortran routine used to compute turbulent fluxes. This routine was distributed as part of LYDS. The bug was identified by L. Brodeau in 20071 and is

\footnotetext{
${ }^{1}$ http://datal.gfdl.noaa.gov/nomads/forms/mom4/CORE/code.html
} 
shown to be responsible for a significant enhancement of tropical evaporation? With this bug corrected, a formerly balanced ocean is expected to yield an excess of heat and freshwater as highlighted by the present study. We also use a non-constant latent heat of vaporization (see Section 2). Using a different coarse grid domain (we are working on the ORCA2 ocean model grid) also introduces differences in the representation of the surface of the ocean (i.e. a different land sea mask) as well as small differences inherent to spatial interpolation when interpolating atmospheric and SST fields onto the chosen domain.

Deeper investigation with results from both the flux calculations and model runs (Section 5) shows that evaporation for DFS3 and LYDS are comparable. Greater evaporation linked to the stronger wind of LYDS is indeed compensated by the greater evaporation resulting from to drier surface air of ERA40 (Section 3.2). In conclusion, the use of ERA40 atmospheric state variables in combination with the radiation and precipitation of LYDS leads to unacceptably high global imbalances that should be decreased by correcting biases and rescaling mean values of the atmospheric fields used in the forcing calculation.

\section{DFS4: an improved ERA40-based forcing dataset}

In this section, we discuss the corrections applied to each field of the DFS3. Our aims for the correction is to yield a realistic time variability of input variables along the 50 years, and to obtain a better regional agreement with some up-to-date climatologies that are usually limited by their spatial and time coverage. Proposed corrections are introduced gradually and their impact on the global heat and freshwater budget is assessed before they are tested with the NEMO $2^{\circ}$ model in Section 5. Table 1 summarizes the main characteristics of the intermediate forcing datasets that have been built between DFS3 and our final dataset, the DFS4, in the procedure of evaluating every individual correction. We start with corrections of surface temperature and humidity (DFS3.1), then add corrections to the wind (DFS3.2), and we finally adjust the downwelling radiation and precipitation to close the global heat and freshwater budget of DFS4. Two hybrid forcing sets which mix NCEP and ERA40 dynamical state variables have also been constructed (LYDS-H1 and LYDS-H2) to answer specific questions raised by the model simulations of Section 5 ,

\subsection{Correction of surface air humidity and temperature}

\subsubsection{Tropical correction}

Fig. 5a shows the monthly-averaged evolution of ERA40 specific humidity in the tropical latitude band between $20^{\circ} \mathrm{S}$ and $20^{\circ} \mathrm{N}$, and highlights three distinct periods bounded by two major discontinuities. In the late seventies, a blunt tropical moistening of about $0.6 \mathrm{~g} / \mathrm{kg}$ can be observed. The only important changes reported by the ECMWF in this period is the 1978-1979 transition. 1979 is particularly important as it marks massive introduction of satellite data as well as surface pressure, temperature and wind data from buoys. The source of infrared radiances data used in the assimilation procedure also changed from VTPR to HIRS/SSU instruments (Uppala et al., 2005). In Fig. 5a though, the transition seems to occur earlier, around 1977. This 1977-like discontinuity may in fact be related to "El Niño". Surface humidity is

${ }^{2}$ http://datal.gfdl.noaa.gov/ z11/mom4/CORE/code/bug_ncar_fluxes.pdf 
a good proxy as surface atmosphere becomes warmer and moister over the eastern equatorial Pacific during such events. Substantial peaks of humidity are indeed found in "El Niño" years, such as the two strong events of 1983 and 1998 (Fig.51a). Weaker events of 1977 and 1978, which are following three consecutive years of strong "La Niña" events (1974, 1975 and 1977), are actually moving the visible discontinuity two years backward. Note that the 1979 tropical moistening problem also affects LYDS (weaker moistening of about $0.3 \mathrm{~g} / \mathrm{kg}$ ), suggesting that NCEP is likely victim of the same issue. The second noticeable discontinuity comes with no surprise at the 2001-2002 transition between ERA40 and EOA (the operational analysis). Years 2002 to 2007 have been dominated by weak to moderate "El Niño" events. The average of our 6 EOA years is thus possibly slightly warmer and moister in the tropics than the climatological mean. However, we chose the average of the EOA for years 2000 to 2007 (2000 and 2001 adding a "La Niña" and a neutral year contribution) as the reference value to rescale humidity. The excellent agreement between LYDS and EOA over the later period (Fig. 5a) is another reason for making this choice. With regards to this reference value, Fig. 5 a highlights that the period $1958-1978$ is likely subject to a dry bias $(-0.3 \mathrm{~g} / \mathrm{kg})$ while the satellite era $(1979-2001)$ is subject to a moist bias $(+0.3 \mathrm{~g} / \mathrm{kg})$.

As a correction, for each of these two periods, the mean inter-tropical surface specific humidity of ERA40 (between $20^{\circ} \mathrm{S}$ and $20^{\circ} \mathrm{N}$ ) is adjusted to fit the aforesaid EOA reference average. ERA40 specific humidity is thus increased by a factor $\alpha_{1}=1.019$ over the first period and decreased by a factor $\alpha_{2}=0.985$ over the second period. The correction factor is linearly blended towards 1 between $20^{\circ}$ and $30^{\circ}$ on both hemispheres. As a result, tropical humidity has the same mean annual value of $16.92 \mathrm{~g} / \mathrm{kg}$ for the three distinct periods (Fig. 5b), insuring interannual continuity and significantly removing trends in the tropical band, and possibly impacting the signature of observed shift in climate. This might limit the range of application of the DFS4 forcing. It allows us to preserve interannual time variability, but may affect multi-decennal time variability (or trends). Air temperature and humidity have to be consistent, and for this reason a similar treatment is applied to the tropical air temperature. The contribution of a small modification of air temperature, which only affects the sensible heat flux, has a negligible impact on the heat budget of tropical regions. Time variability of humidity and temperature over extra-tropical oceans are kept unchanged since no evident biases could be identified.

\subsubsection{Northern corrections}

Fig. 6a compares the climatological seasonal cycle of monthly mean air temperature from POLES (Rigor et al., 2000) and ERA40 over the Arctic (north of $70^{\circ} \mathrm{N}$ ), separating the contribution from ice-covered and ice-free regions. This comparison confirms the warm bias of ERA40 in the Arctic (also see Fig. 4k,d), with a mean value of about $1^{\circ} \mathrm{C}$ warmer over ice. The disagreement is more pronounced over open water but we consider POLES temperatures less reliable than over ice due to a lack of observations; most of the in-situ data used to build this product come from land station or drifting buoys in the ice pack, open ocean values being scarce. While comparing monthly means, we found that regional disagreement between ERA40 and the POLES climatology can locally reach $10^{\circ} \mathrm{C}$ (warmer for ERA40, no figure shown). To correct the ERA40 warm Arctic bias, we opted for a full spatially-dependent monthly rescaling of ERA40 air temperature over ice covered regions north of $70^{\circ} \mathrm{N}$, using a monthly climatological sea-ice mask derived from SSM/I satellite data (Comiso, 1999, updated 2008). To proceed, the mean monthly difference of temperature between POLES and ERA40 (1979-1998) was applied as a corrective offset to the whole ERA40 temperature series, only over ice. Over open ocean, an offset of $-1^{\circ} \mathrm{C}$ was 
applied to ERA40 air temperature north of $70^{\circ} \mathrm{N}$. Air specific humidity was simply corrected to remain consistent with the corrected Arctic temperature. This was done by conserving relative humidity.

Fig. 3b shows that in the $55-65^{\circ} \mathrm{N}$ latitude band, the air temperature in ERA 40 is about $0.25^{\circ} \mathrm{C}$ colder compared to NCEP. As it was noticed in previous DRAKKAR $1 / 4^{\circ}$ simulations with DFS3, the buoyancy loss at these latitudes (and especially in the Labrador Sea) were somewhat excessive (Juza et al., 2009), therefore, a positive offset of $0.25^{\circ} \mathrm{C}$ was applied in this band (linearly decreasing to zero from 55 to $50^{\circ} \mathrm{N}$ and from 65 to $70^{\circ} \mathrm{N}$ ) to make ERA40 consistent with NCEP in this region. On the same basis and for consistency, the air specific humidity was increased by $0.05 \mathrm{~g} / \mathrm{kg}$. We are aware that this modification is questionable since it is guided by the OGCM result. However, the amplitude of the adjustment is set by the difference between NCEP and ERA40 and not by the model results.

\subsubsection{Impact on the global balance}

The above corrections of surface air humidity and temperature slightly increase the net input of heat by $0.7 \mathrm{~W} / \mathrm{m}^{2}$ and decrease the excess of freshwater by about $2 \mathrm{~mm} / \mathrm{year}$ (increase of global evaporation) for the period 1958-2004 (compare DFS3.1 to DFS3 in Table2).

\subsection{Rescaling ERA40 wind}

The study of time variability of ERA40 wind speed reveals important interannual discontinuities especially in the southern hemisphere, as shown in Fig. $7 \mathrm{a}$. These changes in the wind pattern coincide with two important years for ERA40: 1973 and 1979. 1973 marks the beginning of the assimilation of synthetic surface-pressure observations from satellite imagery (PAOBS) and 1979 was previously discussed regarding humidity discontinuities in Section 4.1 . Over the first period (1958-1972), ERA40 wind speed is significantly underestimated when compared to EOA wind (2002-2007), especially from mid to high latitudes (no figure shown), which causes the greater values of the correction factor at these latitudes in Fig. 8 a compared to Fig. $8 \mathrm{~d}$. The period 1973-1978 presents the oddest interannual feature of the whole set of tested ERA40 SAS variables, as wind speed shows very weak values in the ACC latitude band. One may note that NCEP (LYDS) winds show the same southern underestimation of intensity prior to 1979 but without the 1973-1978 Antarctic depletion (Fig.77). The 2001-2002 transition from ERA40 to EOA is smooth but winds are found to be globally stronger after 2002 (likely related to the fact that the model resolution is increased by a factor of 2 after 2001). We consider these interannual discontinuities as artifacts although we are aware that there may be significant trends in the southern hemisphere during that period (Renwick, 2004). In order to reduce them and to correct the global low bias of ERA40 wind, QuikSCAT wind product (Liu et al., 1998) is used. A mean annual climatology of QuikSCAT wind is constructed as the average over the period 2000 to 2007. For each of the four periods determined by 1973, 1979 and 2002, a mean annual ERA40 wind climatology is constructed and used to build four spatially-dependent correction factor maps as the ratio of the QuikSCAT climatology and ERA40 climatology on the given periods:

$$
\alpha_{i}(x, y)=\frac{|\vec{U}|_{\text {QSCAT }}^{2000-2007}(x, y)}{|\vec{U}|_{\text {ERA40 }}^{i}(x, y)} \text { with } i=1958-1972,1973-1978,1979-2001,2002-2007
$$


A threshold of 1.15 is globally applied to $\alpha_{i}\left(\alpha_{i}<1.15\right)$ to avoid extremely high values to be reached in specific regions such as the Warm Pool where QuikSCAT provides excessive wind speeds due to the effect of heavy rain on the sea spotted roughness (Chelton et al., 2006). In such regions, the correction factor can easily reach values beyond 1.6 (gain of 60\%). These correction factors are then smoothed to suppress small scale structures and are linearly blended to 1 in high latitudes regions where QuikSCAT data are missing due to the presence of sea-ice. The result is a calibration factor map for each of the four periods. These factor maps are used to adjust both vector components of the 6-hourly ERA40 wind and are shown in Fig. 8 ,

The corrected winds, together with the corrected air temperature and humidity provide DFS3.2 forcing set (Table11). The impact of the wind increase on both the global budget of heat and freshwater can be assessed by comparing the flux balance between DFS3.1 and DFS3.2 (Table 2). It switches from a warming ocean $\left(+13.5 \mathrm{~W} / \mathrm{m}^{2}\right)$ with an excess of freshwater input $\left(+54 \mathrm{~mm} /\right.$ year) to an almost thermally-balanced ocean $\left(+1.1 \mathrm{~W} / \mathrm{m}^{2}\right)$ with a strong deficit of freshwater $(-86 \mathrm{~mm} /$ year $)$.

\subsection{Correction of radiation and precipitation input}

\subsubsection{Radiation}

Fig. 11 suggests that uncorrected solar input from the ISCCP-FD product is excessive under the tropics. For instance, the non-adjusted NOC 3 climatology (Josey et al., 1998) (formerly SOC), based on ship meteorological reports, sets the maximum of mean annual equatorial insolation to $230 \mathrm{~W} / \mathrm{m}^{2}$ while the ISCCP-FD gives a value near $255 \mathrm{~W} / \mathrm{m}^{2}$. With the limitation of $5 \%$ applied by LY04 in the inter-tropical band, LYDS insolation is reduced to $240 \mathrm{~W} / \mathrm{m}^{2}$. With drier air outside the tropical band (Fig. 3b), ERA40 significantly enhances latent heat loss when compared to NCEP, so the decrease of solar radiation proposed by LY04 over extra-tropical latitudes is not required to balance our global flux. We apply a reduction of $7 \%$ to the ISCCPFD solar radiation in the tropical band $\left(20^{\circ} \mathrm{S}\right.$ and $\left.20^{\circ} \mathrm{N}\right)$. This correction is linearly blended over a $20^{\circ}$ wide latitude bands to ensure meridional continuity (Fig. 1a) with higher latitudes. The main reason for this value of $7 \%$ is to get closer to NOC values. The second reason was to limit a recurrent tropical warm bias observed with different DRAKKAR models forced with a 5\%-decreased solar radiation only. The offset reduction of $5 \mathrm{~W} / \mathrm{m}^{2}$ applied by LY04 on the Arctic is not retained. This adjustment of the downwelling shortwave radiation yields an almostzero global imbalance of heat $\left(+0.3 \mathrm{~W} / \mathrm{m}^{2}\right)$ for the $1958-2004$ period with the prescribed SST approach (DFS4 in Table2).

\subsubsection{Precipitation}

Rescaled ERA40 winds lead to a significant enhancement of global evaporation equivalent to an annual drop of the mean surface height of $86 \mathrm{~mm}$ (Table 2). It is therefore geophysically consistent to increase the global precipitation as a response to this excess of evaporation. The GXGXS product of LY04 is increased by $10 \%$ in the equatorial band $\left(20^{\circ} \mathrm{S}-20^{\circ} \mathrm{N}\right)$ to reach zonal mean precipitation values proposed by Troccoli and Kållberg (2004) when correcting ERA40 (see DFS4 on Fig.1b). Elsewhere precipitation is increased by 5\%. This correction let

\footnotetext{
${ }^{3}$ http://www.noc.soton.ac.uk/JRD/MET/fluxclimatology.php
} 
DFS4 reach a near-zero global imbalance with the prescribed SST approach (DFS4 on Table2) but is somewhat arbitrary as it is set to match our choice of a runoff of $1.3 \mathrm{~Sv}$ (Section 2).

\subsection{Global balance of DFS4}

The DRAKKAR Forcing Set \#4 (DFS4) is constructed by assembling the corrected fields of the ERA40 surface atmospheric variables and the satellite radiation and precipitation (Table1). When computing net heat and freshwater fluxes for the 1958-2004 period with the prescribed SST fields of Hurrell et al. (2008), DFS4 presents an almost-zero global imbalance of heat $\left(+0.3 \mathrm{~W} / \mathrm{m}^{2}\right)$, and freshwater $(-0.2 \mathrm{~mm} /$ year $)$. It is important to note that the corrections applied are such that their impact on fluxes lies within the range of usual flux uncertainties (i.e. less than $10 \mathrm{~W} / \mathrm{m}^{2}$ on the net heat flux, see Fig. 13 for example). Therefore, the major effect of these corrections is not to change the intrinsic realism of the ERA40 forcing, but to significantly improve its consistency (better continuity, correction of unrealistically high trends, nearly equilibrated budget).

\section{Simulations with the NEMO-ORCA2 OGCM}

For every atmospheric dataset presented in this paper, we investigate the sensitivity of the $2^{\circ}$ resolution global model configuration ORCA2 to heat, momentum and freshwater forcing (note that the latter would require a thorough investigation of the response of the sea-ice model which is not performed here). ORCA2 is the model configuration of coarsest resolution in the DRAKKAR hierarchy of global NEMO-based model configurations (The DRAKKAR Group, 2007). It is also the least computationally expensive to run and is well suited to carry out series of multidecadal sensitivity tests.

Integral diagnostics such as global heat and freshwater imbalance, trends in sea-ice extent and thickness, global oceanic volume-averaged temperature and salinity trends, are simple and provide fruitful information about the thermodynamical response of the model. For its major impact on the thermohaline circulation, we also analyze the production of dense water in the Nordic seas by studying the Atlantic meridional overturning circulation (AMOC) and the mixed layer depth (MLD). Model-data comparison of SST helps assessing the relevance of both the heat and momentum forcing. Namely, we quantified global mismatch between modeled SST and the reconstructed interannual SST climatology of Hurrell et al. (2008).

\subsection{Ocean Sea-Ice Circulation Model}

The numerical code used to perform simulations of the ocean/sea-ice circulation is NEMO (Madec, 2008). It comprises the most recent version of the ocean general circulation model formerly known as OPA (Madec et al. . 1998) coupled to the sea-ice model LIM2 of Fichefet and Maqueda (1997). The bathymetry is represented as partial steps. The code solves the standard primitive equations, using a free surface formulation. At coarse resolution as used here (about $2^{\circ}$ ), the effects of the subgridscale processes (mainly the mesoscale eddies) are represented by an isopycnal mixing/advection parameterization as proposed by Gent and McWilliams (1990). A bottom boundary layer scheme, similar to that of Beckmann and Döscher (1997) is used to improve the representation of dense water spreading. The surface boundary layer mixing and the interior vertical mixing are parametrized according to a local turbulent kinetic energy 
(tke) closure scheme, adapted to NEMO from that proposed by Blanke and Delecluse (1993). The model configuration used is the so called "ORCA2 configuration". The global ORCA2 tripolar grid (Madec and Imbard, 1996) extends from $78^{\circ} \mathrm{S}$ to $90^{\circ} \mathrm{N}$. The grid is nearly isotropic with a resolution of $2^{\circ}$. A grid refinement from $2^{\circ}$ to $0.5^{\circ}$ is progressively applied in the latitude direction only in a zonal band along the equator. The vertical grid has 31 levels, with a resolution ranging from $10 \mathrm{~m}$ at the surface to $500 \mathrm{~m}$ at the bottom. This model configuration has been used extensively over the last 10 years with the older versions of the OPA and LIM codes (e.g. Timmermann et al., 2005).

In a model forced by an observed atmospheric state (with bulk formulae) rather than coupled to an interactive atmosphere, there is no feedback between the ocean and precipitations. The resulting model drift is made worse by the large uncertainties of the precipitation fields. For this reason we choose to apply a restoring of surface salinity to the climatology of Levitus et al. (1998). A comparison of 7 different models forced by the "normal year" forcing of LY04 showed that most models (including ORCA2) produce unrealistic solution with a weak salinity relaxation (Griffies et al., 2009), one of the consequences being the weakening of the thermohaline circulation. In the present study, we use a rather strong salinity restoring, corresponding to a relaxation time scale of 33 days for the first model level $(10 \mathrm{~m})$, in the open ocean as well as under sea ice. Note that this will significantly constrain the freshwater balance in our experiments.

ORCA2 is initialized in 1958 with the temperature and salinity climatology of Levitus et al. (1998) and is run for 47 years until the end of 2004. Surface fluxes used to drive the simulations are computed using strictly the same method (i.e. same flux calculation algorithm and input data) as used in the offline calculation of sections 2 and 3, except that the prognostic SST and sea-ice concentration of the model are used rather than prescribed observations. Note that NEMO handles solar penetration, therefore, $Q_{s w}$, the radiative shortwave component of the net heat flux, must be explicitly specified. The run being fully-interannual from 1984 onward (constrained by radiation data) we only consider this later period for time-averaged diagnostics.

\subsection{DFS3 driven runs}

\subsubsection{AMOC and mixed layer depth}

As we used the LYDS forcing dataset as reference in the previous sections, the run driven by the LYDS forcing is used to evaluate the impact of the DFS forcing series developed in this study. Averaged strength of the AMOC is weak in the LYDS-driven run (Fig.9). After a sharp decrease during the first 10 years of simulation (a dynamical adjustment from initial conditions), the AMOC maximum value remains of the order of $12 \mathrm{~Sv}$, a weak value compared to observationbased estimates of $16 \pm 2 \mathrm{~Sv}$ at $48^{\circ} \mathrm{N}$ of Ganachaud (2003) or Lumpkin and Speer (2007). The variability of the AMOC is very similar in all simulations whether LYDS or ERA40 are used, which indicates that the datasets used in this study have comparable interannual variability. After the initial adjustment, the AMOC shows a regular increase from the mid 70's to the mid 90's, a period characterized by an increasingly high NAO index (Hurrell, 1995) and strong oceanic convection in the Labrador Sea (Yashayaev et al., 2003). The maximum (13.5 Sv in LYDS, 15 to $17 \mathrm{~Sv}$ in other experiments) is reached in 1999. A sharp decrease of the AMOC occurs in the early 2000's, a period of reduced oceanic deep convection in the northern North Atlantic (Yashayaev et al., 2003). The mid 70's to the mid 90's increase and the early 2000s 
decrease of the AMOC are driven by the forcing, but their exact amplitudes have to be corrected of the slow trend due to the model adjustment from initial conditions, trend that a 50 year long experiment does not permit to estimate (Griffies et al., 2009). The LYDS run also shows the shallowest late-winter MLD in the North Atlantic of all tested configurations (Fig. 10a). Furthermore, we also noticed the limited ability of the LYDS forcing to produce the dense waters required to maintain reasonable values of the overflow. This finding is consistent with Griffies et al. (2009) and Biastoch et al. (2008) who found similarly weak AMOC when their model is forced with LYDS. When using climatological version of the LYDS (the so-called "normal year" forcing), Griffies et al. (2009) find that without a strong restoring to sea surface salinity the AMOC collapses in ORCA2. We have verified that this is also the case for the interannual LYDS. In order to maintain the AMOC at an acceptable level with LYDS, Biastoch et al. (2008) use a three dimensional relaxation of temperature and salinity in the polar regions.

The most spectacular change linked to the use of DFS3 is the enhancement of the AMOC by about $2 \mathrm{~Sv}$ compared to LYDS (see Fig.99). To discriminate between the contribution of the wind and that of the air temperature-humidity couple, hybrid configurations, mixing variables from ERA40 and LYDS, have been tested. To preserve thermodynamic consistency, surface air temperature and humidity are always taken from the same origin. The alternative tests we performed estimate separately the influence of changing the wind speed from LYDS to ERA40 on one hand, and the surface temperature and humidity on the other hand. This is still meteorologically inconsistent though, and the two following forcing sets are only used for investigation purposes, and are not considered as acceptable forcing sets. LYDS-H1 only differs from LYDS by the use of ERA40 wind while LYDS-H2 only differs from LYDS by the use of ERA40 air specific humidity and temperature (Table1). As shown in Fig.9, replacing LYDS winds by ERA40 winds (run LYDS-H1) has no significant impact on the AMOC, whereas changing air humidity and temperature (run LYDS-H2) results in an increase of about $2 \mathrm{~Sv}$. Fig.10 illustrates the impact of ERA40 SAS variables on the deepening of the late winter MLD, especially in the Labrador sea where the maximum mean march MLD reaches about $800 \mathrm{~m}$ in LYDS and $1400 \mathrm{~m}$ in DFS3. The increased buoyancy loss resulting from the dryer and colder air of ERA40 in deep convection regions (Section 3.2, Fig. 4a and 4k), enhances convection which as a direct impact on the MLD and the AMOC. This high sensitivity of the AMOC to the air humidity and temperature underlines the role of turbulent heat fluxes in setting the mean strength of the model overturning, and probably also its long term variability, via the formation of dense waters.

\subsubsection{Global trends}

The time evolution of the globally averaged ocean temperature is shown in Fig.11a. LYDS leads to a significant increase of the ocean heat content between 1958 and 2004 especially marked at $100 \mathrm{~m}$ (Fig. $11 \mathrm{~b}$ ) and principally located in the tropical Atlantic ocean (no figure shown). The ocean warmed by $0.093^{\circ} \mathrm{C}$ in global average in 47 years (Fig. 11 la), which corresponds to a net heat imbalance of about $+0.9 \mathrm{~W} / \mathrm{m}^{2}$ compared to $+10.4 \mathrm{~W} / \mathrm{m}^{2}$ obtained with the prescribed SST method (Table2). This highlights the strong correcting feedback applied by the SST on the net heat flux when forcing with the bulk method. Differently, DFS3 leads to an almost perfectly balanced ocean corresponding to a zero heat imbalance during the 1958-2004 period. The surface tropical warming of the ocean is less efficient with DFS3 due to the reduction of vertical mixing (due to lower winds). Warm surface waters tend to stagnate more, introducing 
a warm bias in tropical SST, compare Fig. $12 \mathrm{a}$ to $12 \mathrm{~b}$. This leads to a stronger stratification and higher latent and infrared heat losses, thereby reducing the net amount of heat gained by the ocean. Fig. 11b shows that the excellent global heat balance in DFS3 is characterized by a lesser warming in the upper layer of the ocean (0-300 m) than in LYDS, and a cooling between $300 \mathrm{~m}$ and $1500 \mathrm{~m}$. We link this deep cooling to the weaker intensity of ERA40 winds compared to LYDS. ERA40 wind produces subtropical gyres that are too shallow, thereby heaving isopycnals and the main thermocline, and creating a cold temperature bias around $700 \mathrm{~m}$.

The freshwater forcing in DFS3 differs from that in LYDS only by the evaporation term which is driven by surface atmospheric state variables. As seen on Fig.11, the global budget of freshwater (illustrated here by the time evolution of the model sea surface height, $\mathrm{SSH}_{4}^{4}$ ), follows a similar pattern in both runs, a rapid increase of the sea level during an initial period followed by a steady decrease. Note that this initial period is significantly longer in DFS3 and DFS3.1 runs, an indication that it is linked to the strength of the wind (stronger winds yielding a shorter period of adjustment). In accordance with our preliminary analysis of the freshwater budget (Table 2), the excess of freshwater is higher with DFS3 $(+7 \mathrm{~mm} /$ year versus $+4 \mathrm{~mm} /$ year for LYDS), globally freshening the ocean. Note that the relevance of the above comparisons have to be moderated by the impact of the SSS relaxation, the amplitude of which largely overcomes that of the changes discussed (the freshwater flux induced by the SSS relaxation is estimated to be of the order of $40 \mathrm{~mm} / \mathrm{year}$ ). Fig. $11 \mathrm{~d}$ shows that in both runs, the global ocean freshens in the upper layers (from the surface to $700 \mathrm{~m}$ ) and becomes saltier below. When switching from LYDS to ERA40 surface atmospheric state (DFS3) the dynamical response induced by the change in wind intensity dominates and is limited at the surface by increased evaporation. In the main thermocline, between $200 \mathrm{~m}$ and $1000 \mathrm{~m}$, the freshening is increased with DFS3 by the heaving of isopycnals in subtropical gyres induced by the weaker ERA40 winds. At the surface, the globally dryer air of ERA40 (except in the equatorial band) enhances evaporation, and the freshening of the 200 first meters is consequently reduced.

\subsubsection{SST and sea-ice}

Compared to climatology (Hurrell et al., 2008), the surface temperature simulated with the LYDS forcing fields is too high in tropical regions, especially at the eastern boundary south of the equator (Fig. 12 $\mathrm{a}$ ). This is however not the case in the upwelling band of the equatorial eastern Pacific which exhibits colder surface waters. This could be due to the inability of the coarse-resolution model to account for the meridional mixing linked to tropical instability waves, although other processes such as a too strong upwelling, too strong vertical temperature gradient, or the lack of nocturnal mixing might also be involved. DFS3 amplifies this tropical warm surface bias (compare Fig $12 \mathrm{a}$ and $\mathrm{b}$ ). This is due to the less efficient wind-driven vertical mixing previously discussed and to the fact that evaporation, which should normally increase due to the higher SST and thus limit this surface heating, is also limited by the weaker winds and the moister inter-tropical air of ERA40 (no figure shown). As a result, values of zonally-averaged latent heat flux in the tropical band are almost identical in LYDS and DFS3 runs (no figure shown). The excess of evaporation induced by the warm SST bias is thus entirely balanced by the deficit due to the weaker winds and moister tropical air in DFS3. DFS3

\footnotetext{
${ }^{4}$ In NEMO, the variations of the basin averaged SSH reflects the global freshwater balance because the SSS relaxation term is not included in the forcing of the free surface
} 
also leads to an underestimation of Arctic sea-ice extent and ice volume. Winter and summer extension of sea-ice in the Arctic ocean (mean values for March and September) predicted by the model are compared to observed data from the SSM/I between 1979 and 2004 (Comiso, 1999, updated 2008) in Fig. 6b. All tested forcing sets underestimate the total area covered by sea-ice in winter by more than $10^{6} \mathrm{~km}^{2}$. LYDS leads to the lowest estimation while DFS3 (despite warmer temperatures over ice) slightly increases the winter ice extension. However, colder winter temperatures of LYDS are responsible for enhancing ice production more than ERA40 which explains why its summer ice extent is more important, and closer to observations. The summer representation of ice extent is very satisfying for the LYDS-driven run, while it is evident that SAS variables of ERA40 used in DFS3 lead to an underestimation of almost $210^{6} \mathrm{~km}^{2}$. This is likely linked to excessively warm temperatures (Fig. 4 d). Note that similar flaws are also identified in simulations carried out under LYDS forcing with the same model at a resolution of 1/4 (Lique et al., 2009; The DRAKKAR Group, 2007).

\subsection{Model sensitivity to corrections in DFS4}

\subsubsection{Humidity and temperature correction}

The DFS3.1 simulation is similar to DFS3, but uses the air humidity and temperature corrections described in Section 4.1. The drying of the surface air applied in DFS3.1 in the tropics during the last two decades enhances the evaporation term which is expected to affect both heat and freshwater forcing. A comparison between the SST fields of DFS3 and DFS3.1 runs (Fig. 12 b,c) shows that the correction slightly decreases the warm bias in the tropics, but this remains insufficient since the difference with climatology remains of the order of $+0.5^{\circ} \mathrm{C}$. Fig. 13a shows that our correction increases the latent heat loss by about $2 \mathrm{~W} / \mathrm{m}^{2}$ (up to $3.5 \mathrm{~W} / \mathrm{m}^{2}$ at the Equator, see the curve for DFS3.1) and is partly balanced by the decrease of sensible and infrared heat losses due to the sea surface cooling (Fig.13b,c). This explains why the net heat flux is weakly modified by the introduction of the tropical humidity correction (Fig. 13 d). The resulting extra equatorial heat loss is balanced by the decrease in heat loss linked to our northern correction (Section 4.1.2). Therefore, like DFS3, DFS3.1 leads to a zero imbalance of heat (Fig.119 and Table2). Due to the surface salinity restoring, the effect on surface salinity is hardly discernible. Globally the ocean is freshening slightly more than with DFS3 (freshwater imbalance of $+8 \mathrm{~mm} /$ year, Fig. $11 \mathrm{k}$ and Table 2). The correction of the Arctic temperature also improves the representation of the Sea-ice extent, which becomes more realistic, especially in summertime (Fig.6b). The northern correction applied to ERA40 actually yields shallower winter MLDs in the Nordic Seas compared to DFS3 (no figure shown). This is accompanied by reduction in the mean annual maximum of the AMOC by roughly $0.3 \mathrm{~Sv}$.

\subsubsection{Rescaled wind}

Simulation DFS3.2 uses rescaled wind defined in Section 4.2 in addition to the air temperature and humidity corrections already included in DFS3.1. As expected, evaporation is significantly enhanced (Fig.13a), leading to a significant deficit of freshwater input (compare DFS3.2 to DFS3.1 on Fig.11 c). This also cools the SST almost everywhere (Fig.12k,d). The warm surface inter-tropical bias is thus reduced, but mid-latitude surface temperature cold biases are increased. The cold bias at $700 \mathrm{~m}$ discussed in Section 5.2.2 and linked to the heaving of isopycnal in subtropical gyres due to weak amplitude of ERA40 winds, disappears with use of our 
rescaled wind (Fig.11b). This is an indication that the wind driven circulation is improved at mid latitudes.

Unexpectedly, using stronger winds lets the ocean globally gain heat (imbalance of $+0.3 \mathrm{~W} / \mathrm{m}^{2}$ compared to 0 for DFS3 and DFS3.1, Fig.11a and Table 2). Since changing the wind affects every turbulent flux, the interpretation of the model response to modified winds is made easier if the mechanical and the thermohaline impacts of the wind are decoupled. To achieve this, the model has been driven with an intermediate forcing function, based on that used for DFS3.1, in which turbulent heat fluxes are computed using uncorrected wind from ERA40 while wind stress is computed using rescaled ERA40 winds. The wind increase is thus only applied to the momentum forcing. This run, named HW2, is started in 1984 with the ocean state of run DFS3.1 (end of 1983) as initial condition. This forcing leads to the sharpest rise in global oceanic volume-averaged temperature as shown in Fig.14a. Stronger winds enhance vertical shears in the upper layers, increasing the efficiency of the TKE mixing which leads to a more efficient diffusion of heat downward. If our diagnostic clearly identifies the contribution of the enhanced mixing to this warming, we cannot exclude a contribution of the Ekman pumping (vertical advection). But that contribution which has not been calculated in this study, could be small since it is the balance of the contributions of opposite signs from upwelling and downwelling regions. Fig. 14b confirms that vertical diffusivity is greater in the first hundred meters in the experiments driven by stronger winds (DFS3.2 and HW2). The enhancement of the surface vertical mixing tends to decrease the feedback of SST on heat fluxes by making the SST less responsive to these fluxes. This positive feedback on temperature is still active in DFS3.2 but is mitigated by the increase of evaporative heat loss.

The surface cooling also has a positive impact on the increasing ocean heat content by limiting turbulent and infrared heat losses (Fig. $13 \mathrm{~b}, \mathrm{c}$ ). Note that the volumetric warming of the ocean induced by the rescaled winds could not have been pointed out without the use an OGCM. Run HW2 was also useful in assessing the "momentum-increase-only" contribution to the surface temperature change. It has a direct cooling effect in upwelling zones (equatorial and west coasts) and subpolar regions (including the ACC). It also has a warming effect on all western boundary currents due to the strengthening of the wind-driven subtropical gyre (no figure shown). The sea surface equatorial cooling is responsible for significantly increasing the net heat flux with a maximum of $8 \mathrm{~W} / \mathrm{m}^{2}$ at the Equator (Fig. $13 \mathrm{~d}$ ).

Fig. 14k. shows that run HW2 exhibits the weakest AMOC, indicating that the increased mechanical forcing has a very small impact on the AMOC. Interestingly, run DFS3.2 shows the strongest AMOC. This proves that the enhancement of the AMOC (about $0.5 \mathrm{~Sv}$ ) resulting from our wind rescaling is entirely attributable to the increase in turbulent heat losses. Indeed, a comparison of mean march MLDs between runs DFS3.1, HW2 and DFS3.2 also confirms that only the enhanced buoyancy loss in Nordic seas is responsible for deepening the MLD (no figure shown). The response of the model is somewhat different in extra-tropical to mid latitude bands where the stronger momentum input substantially deepens the MLD.

The representation of Pacific EUC is improved when using rescaled winds except in the very western Pacific where uncorrected ERA40 winds still yield the best results (Fig. 15). Still, the EUC remains underestimated of about $0.2 \mathrm{~m} / \mathrm{s}$ in eastern Pacific, which is likely the result of an inadequate sub-grid-scale parameterization in our coarse-resolution model (Cravatte et al., 2007). EUC transport has proved to be very sensitive to model resolution and is expected to increase with finer resolutions. In-situ measurements of the ACC conducted by several authors 
at the Drake passage give transport estimates close to $140 \mathrm{~Sv}$ with an uncertainty of $10 \mathrm{~Sv}$ (Macdonald and Wunsch, 1996). Forcing the model with the rescaled ERA40 wind strengthens the ACC by roughly $4 \mathrm{~Sv}$, leading to a transport of about $150 \mathrm{~Sv}$. This strong value is probably attributable to the coarse-resolution of our model as Treguier et al. (2007) report lower values in the $1 / 4^{\circ}$ global DRAKKAR model.

\subsubsection{Radiative and freshwater adjustment}

The Drakkar Forcing Set \#4 (DFS4) is defined after every correction discussed in Section 4 is applied to the original DFS3. Compared to intermediate version DFS3.2, it only differs by the inclusion of the downwelling shortwave radiation and precipitation adjustments. The 7\% decrease of ISCCP downwelling shortwave radiation in low latitude (5\% in all previous runs) tends to degrade the equatorial representation of SST with our coarse-resolution model with regards to DFS3.2 (Fig. 12 d,e). The tropical ocean becomes slightly too cold compared to observations (Hurrell et al., 2008). Southward of $35^{\circ} \mathrm{S}$, as we revert to original ISCCP values (Fig.11a), the SST representation is improved as the excess of solar radiation contributes to limit the cold bias.

With the bulk method, the warming (or cooling) impact of any increase (or decrease) of the downwelling radiative flux received by the ocean is strongly limited by the negative feedback induced by the modification of the SST which tends to decrease (or increase) turbulent and infrared heat losses. For instance, despite adding roughly $7 \mathrm{~W} / \mathrm{m}^{2}$ of solar radiation at $40^{\circ} \mathrm{S}$ between DFS3.2 and DFS4 (Fig.11a), the net heat flux is not affected as seen in Fig.13d. This is principally due to the substantial enhancement of the latent heat loss of $7 \mathrm{~W} / \mathrm{m}^{2}$ (Fig. 13 a). In contrast with results obtained with the prescribed SST (Table2) our correction worsens the volumetric warming of the ocean $\left(+0.1 \mathrm{~W} / \mathrm{m}^{2}\right.$ compared to DFS3.2) and is particularly marked in the first $500 \mathrm{~m}$ (Fig.11a,b). Nevertheless, global balances of heat and freshwater for the 19582004 period remain good (respectively $+0.4 \mathrm{~W} / \mathrm{m}^{2}$ and $+0.6 \mathrm{~mm} /$ year, Table 2). Again, to place these numbers in their context, we recall that the freshwater balance is by far dominated by the relaxation to sea surface salinity in our simulations. Due to the important increase of evaporation in the southern hemisphere (Fig.13 a), resulting from the adjustment of downwelling radiation, our precipitation adjustment has almost no impact on the "global salinization" of the first $100 \mathrm{~m}$ already observed with DFS3.2 (Fig.11k,d). However, the vertical representation of salinity is improved beyond $100 \mathrm{~m}$. Increasing both radiation and precipitation increases the buoyancy of surface waters, the maximum of the mean march MLD, located in the Labrador sea, reaches $1480 \mathrm{~m}, 35 \mathrm{~m}$ shallower than with DFS3.2.

\section{Summary and concluding remarks}

The comparison of atmospheric fields of the Large and Yeager (2004) dataset (LYDS) and ERA40 highlighted a few noteworthy facts regarding datasets routinely used to force OGCMs. First, winds from the two major reanalyzes (NCEP and ERA40) tend to be underestimated when compared to more trustworthy data such as scatterometer wind products (QuikSCAT). Second, surface atmospheric state variables of ERA40, and to a lesser extent those of NCEP, suffer from time discontinuities related to the evolution of the origin of data used in their respective assimilation process. Finally, downwelling radiation components and precipitation data of reanalyzes are not reliable and satellite products stand as better alternatives. A first forcing data set, DFS3, 
is thus constructed by assembling the ERA40 surface atmospheric state variables with radiation and precipitation from LYDS, but the global heat and freshwater budget computed with DFS3 and observed SST is found to be unbalanced. A set of corrections was applied to both atmospheric and radiation fields of the DFS3, our initial ERA40-based dataset. They include a time-dependent recalibration of surface atmospheric fields of ERA40 in the tropical band, readjustments of Arctic air temperature and humidity based on the POLES climatology, a global increase of the wind speed based on QuikSCAT values, and zonal adjustments of the downwelling radiation and precipitation products proposed by Large and Yeager (2004). One of the constraint was to reach a near-zero global imbalance of heat and freshwater when computing fluxes with a prescribed climatological surface state of the ocean. Note that the amplitude of the corrections are small and such that their impact on fluxes lies within the range of usual flux uncertainties (i.e. less than $10 \mathrm{~W} / \mathrm{m}^{2}$ ).

Global simulations performed with ORCA2, a coarse-resolution ocean/sea-ice circulation model forced with surface atmospheric state variables of ERA40 showed several differences with respect to LYDS-driven simulations. These include an increase of the AMOC from 12 to $14 \mathrm{~Sv}$. Further efforts to force the model with hybrid forcing functions permitted to link this modification of the AMOC intensity to the enhancement of surface buoyancy loss in the Nordic seas and the Northern North Atlantic. DFS4, our final ERA40-based dataset, is shown to preserve positive features of DFS3 while significantly correcting its major flaws, such as tropical warm bias, weak wind driven circulation in subtropical gyres and the ACC, and unrealistic arctic ice cover. Representation of the vertical structure of temperature is also improved when compared to the solution of the LYDS-driven run (Fig.11b). However, the ocean surface remains globally cooler than observations (Fig. 12k) and significant differences persist in the vicinity of the largest currents (Gulf Stream, Kuroshio, Agulhas, Brazil-Malvinas confluence, ACC). They are caused by known model dynamical biases due to numerics and coarse-resolution (position of Gulf Stream, overshoot of western boundary currents, etc). We expect these to be significantly reduced at the eddy-resolving resolution. Still, possible sources of error are likely to arise from missing elements like the diurnal cycle of shortwave heating, or the spatially-varying chlorophyll-dependent solar penetration into the water column. As it has been shown in several model studies, both aspects can have major impacts on the climatological SST, mixed-layer depth, and interannual variability, especially in weakly-stratified regions like the tropical warm pools (see Bernie et al., 2007. 2008, for the diurnal cycle, and Lengaigne et al., 2007. Anderson et al., 2009 for the chlorophyll dependency of solar penetration).

As highlighted by Table 2 , and especially for our intermediate forcing configurations, prescribed SST studies are weak in predicting the actual response of a bulk-driven OGCM to a given forcing set. This is mainly due to the important role played by the SST when estimating both heat and freshwater fluxes. Interestingly, with DFS4, a good agreement is found between the two approaches. When tested with the observed SST, DFS4 leads to an almost closed budget of heat and freshwater for the $1958-2004$ period (respectively $+0.3 \mathrm{~W} / \mathrm{m}^{2}$ and $-0.2 \mathrm{~mm} /$ year), the same fluxes computed interactively with ORCA2's SST lead (for the same period) to an annual imbalance of heat and freshwater of respectively $+0.4 \mathrm{~W} / \mathrm{m}^{2}$ and $+0.6 \mathrm{~mm}$. Prescribed SST diagnostics cannot account for the modification of evaporation induced by a radiation adjustment, which proved to have a significant impact on both heat and freshwater budgets of the ocean when using our model. The corrective feedback applied by the SST on the net heat flux has also been verified as global imbalances of heat computed by the model were always much closer to 
zero than those computed with the prescribed SST approach.

The response of our coarse-resolution model to the different atmospheric datasets, has shown some counter-intuitive sensitivities. The strengthened winds, as expected, enhance heat loss through evaporation, but also globally warm the ocean by increasing the vertical mixing. Enhanced vertical diffusion helps maintain a cooler SST, which tends to limit the amount of heat lost by the ocean (through turbulent and infrared heat losses), thereby allowing the ocean to store more heat. Surface atmospheric state variables, through their direct influence on turbulent heat fluxes, are shown to play a significant role on important features of the ocean circulation such as the AMOC, tropical SST representation, etc. Surface atmospheric state variables from NCEP and ERA40 lead to distinct solutions for trends and mean state. However, interannual and decadal variability of the simulated circulation features are similar, indicating that atmospherically driven variability is similar in both reanalysis products. Modification of the downwelling radiation input is partially balanced by the response of the SST-dependent heat fluxes which tend to limit the impact of such modifications.

In conclusion, we propose a new set of forcing variables for OGCMs based on ERA40 which provide an alternative to LYDS, and that can be used to perform ocean hindcasts of the last 5 decades. The DFS4 dataset is currently extended to year 2007, and will be made available on request by the Drakkar group. Generally, it should permit further sensitivity studies to atmospheric forcing during this period. Surface atmospheric variables from reanalysis products should still be improved further to provide better forcing fields for ocean models, and we are now investigating the latest reanalysis of ECMWF, ERA-interim (1989 to present).

\section{Acknowledgments}

The authors acknowledge support from Centre National de la Recherche Scientifique (CNRS), Université Joseph Fourier (UJF) de Grenoble and IFREMER in Brest. This study, carried out as part of the DRAKKAR project, was supported by grants from SHOM, CNES, GMMC and MERCATOR-Ocean, INSU/CNRS (PICS 2475), and by the European Integrated project MERSEA. Computer resources were provided by Institut du Développement et des Resources en Informatique Scientique (IDRIS) in Orsay and the MIRAGE platform in Grenoble.

\section{References}

Anderson, W., Gnanadesikan, A., Wittenberg, A., 2009. Regional impacts of ocean color on tropical Pacific variability. Ocean Science 5, 313-327. 19

Andersson, E., Bauer, P., Blazon, A., Chevallier, F., Ólm, E., Janisková, M., Kållberg, P., Kelly, G., Lopez, P., McNally, A., Moreau, E., Simmons, A., Thépaut, J. N., Tompkins, A., Andrae, U., Sokka, N., Onogi, K., 2005. Assimilation and modeling of the atmospheric hydrological cycle in the ECMWF forecasting system. Bull. Am. Meteorol. Soc. 86, 387-402. 6

Baumgartner, A., Reichel, E., 1975. The world water balance, mean annual global, continental and maritime precipitation, evaporation and runoff. Elsevier, p. 179. 4

Beckmann, A., Döscher, R., 1997. A method for improved representation of dense water spreading over topography in geopotential-coordinate models. J. Phys. Oceanogr. 27, 581-591. 12 
Béranger, K., Barnier, B., Gulev, S., Crépon, M., 2006. Comparing twenty years of precipitation estimates from different sources over the world ocean. Ocean Dynamics 56, 104-138. 6

Bernie, D. J., Guilyardi, E., Madec, G., Slingo, J. M., Woolnough, S. J., 2007. Impact of resolving the diurnal cycle in an ocean-atmosphere GCM. Part 1: A diurnally forced OGCM. Climate Dynamics 29, 575-590. 19

Bernie, D. J., Guilyardi, E., Madec, G., Slingo, J. M., Woolnough, S. J., 2008. Impact of resolving the diurnal cycle in an ocean-atmosphere GCM. Part 2: A diurnally coupled CGCM. Climate Dynamics 31, 909-925. 19

Biastoch, A., Böning., C., Getzlaff, J., Molines, J.-M., Madec, G., 2008. Mechanisms of interannual - decadal variability in the meridional overturning circulation of the mid-latitude north atlantic ocean. J. Climate 21, 6599-6615. 14

Blanke, B., Delecluse, P., 1993. Variability of the tropical atlantic ocean simulated by a general circulation model with two different mixed-layer physics. J. Phys. Oceanogr. 23, 1363-1388. 13

Brodeau, L., 2007. Contribution à l'amélioration de la fonction de forçage des modèles de circulation générale océanique. Ph.D. thesis, Université Joseph Fourier, Grenoble, France. 2

Chelton, D. B., Freilich, M. H., Sienkiewicz, J. M., Von Ahn, J. M., 2006. On the use of QuikSCAT scatterometer measurements of surface winds for marine weather prediction. Mon. Wea. Rev. 134, 2055-2071. 11

Comiso, J., 1999, updated 2008. Bootstrap sea ice concentrations from NIMBUS-7 SMMR and DMSP SSM/IBoulder, Colorado USA: National Snow and Ice Data Center. Digital media. 9 , 16

Cravatte, S., Madec, G., Izumo, T., Menkes, C., Bozec, A., 2007. Progress in the 3-d circulation of the eastern equatorial pacific in a climate ocean model. Ocean Modelling 17, 28-48. 17

Fekete, B. M., Vörösmarty, C. J., Grabs, W., 2000. Global composite runoff fields based on observed river discharge and simulated water balances. Tech. rep., Global Runoff Data Centre Rep. 22, Koblenz, Germany, 39 pp. 4

Fichefet, T., Maqueda, M. M., 1997. Sensitivity of a global sea ice model to the treatment of ice thermodynamics and dynamics. J. Geophys. Res. 102 (12), 609-646. 12

Ganachaud, A., 2003. Large scale mass transports, water mass formation and diffusivities estimated from the woce hydrographic data. J. Geophys. Res. 108. 13

Gent, P. R., McWilliams, J. C., 1990. Isopycnal mixing in ocean circulation models. J. Phys. Oceanogr. 20, 150-155. 12

Gibson, J. K., Kållberg, P., Uppala, S., Hernandez, A., Nomura, A., Serrano, E., 1997. ERA description. ECMWF Reanalysis Project Rep. 1, 72 pp. 2,5

Global Runoff Data Centre, 2000. Observed historical discharge data from major rivers for climate model validation. Tech. rep., Max Planck Institute. 4 
Griffies, S., Biastoch, A., Boning, C., Bryan, F., Danabasoglu, G., Chassignet, E., England, M., Gerdes, R., Haak, H., Hallberg, R., Hazeleger, W., Jungclaus, J., Larg, W., Madex, G., Samuels, B., Scheinert, M., Severijns, C., Simmons, H., Treguier, A., Winton, M., Yeager, S., J., Y., 2009. Coordinated Ocean-ice Reference Experiments (COREs). Ocean Modelling 11, 59-74. 1, 13, 14

Huffman, G. J., Adler, R. F., P. A., A., Chang, A., Ferraro, R., Gruber, A., Janowiak, J., Joyce, R. J., McNab, A., Rudolf, B., Schneider, U., Xie, P., 1997. The global precipitation climatology project (gpcp) combined precipitation data set. Bull. Amer. Meteor. Soc. 78, 5-20. 5

Hurrell, J. W., 1995. Decadal trends in the north atlantic oscillation: Regional temperatures and precipitation. Science 269 (5224), 676-679. 13

Hurrell, J. W., Hack, J. J., Shea, D., Caron, J. M., Rosinski, J., 2008. A new sea surface temperature and sea ice boundary dataset for the community atmosphere model. J. Climate 21 (19), 5145-5153. 4, 12, 15, 18, 34

Jacobs, S., Comiso, J., 1989. Sea ice and oceanic processes on the Ross Sea continental shelf. J. Geophys. Res. 94, 18195-18211. 4

Josey, S. A., Kent, E. C., Taylor, P. K., 1998. The Southampton Oceanography Centre (SOC) Ocean - Atmosphere Heat, Momentum and Freshwater Flux Atlas. Tech. rep., Southampton Oceanography Centre, 30 pp. 11

Juza, M., Penduff, T., Barnier, B., Brankart, J.-M., 2009. Analysis of monthly ARGO sampling errors in the global ocean mixed layer: a DRAKKAR model study, Submitted to J. Geophys. Res. - Ocean. 10

Kalnay, E., Kanamitsu, M., Kistler, R., Collins, W., Deaven, D., Gandin, L., Iredell, M., Saha, S., White, G., Woollen, J., Zhu, Y., Chelliah, M., Ebisuzaki, W., Higgins, W., Janowiak, J., Mo, K., Ropelewski, C., Wang, J., Leetmaa, A., Reynolds, E., Jenne, R., Joseph, D., 1996. The NCEP/NCAR 40-year reanalysis project. Bull. Amer. Meteor. Soc. 77, 437-471. 2

Large, W. G., Danabasoglu, G., Doney, S. C., McWilliams, J. C., 1997. Sensitivity to surface forcing and boundary layer mixing in a global ocean model. J. Phys. Oceanogr. 27, 24182447. 3

Large, W. G., Yeager, S. G., 2004. Diurnal to decadal global forcing for ocean and sea-ice models. NCAR technical note, 22 pp. 1, 3, 7, 18, 19, 25

Large, W. G., Yeager, S. G., 2008. The global climatology of an interannually varying air-sea flux data set. Climate Dynamics, doi: 10.1007/s00382-008-0441-3. 2

Leeuwenburgh, O., 2005. Assimilation of along-track altimeter data in the tropical Pacific region of a global OGCM ensemble. Quart. J. Roy. Meteor. Soc. 131, 2455-2472. 3

Lengaigne, M., Menkes, C., Aumont, O., Gorgues, T., Bopp, L., André, J.-M., Madec, G., 2007. Influence of the oceanic biology on the tropical Pacific climate in a coupled general circulation model. Climate Dynamics 28, 503-516. 19 
Levitus, S., Boyer, T. P., Conkright, M. E., O’Brien, T., Antonov, J., Stephens, C., Stathoplos, L., Johnson, D., Gelfeld, R., 1998. NOAA Atlas NESDIS 18 and WORLD OCEAN DATABASE 1998. Vol. 1. U.S. Gov. Printing Office, Wash., D.C. 13

Lique, C., Treguier, A.-M., Scheinert, M., Penduff, T., 2009. A model-based study of ice and freshwater transport variabilities along both sides of Greenland. Climate Dynamics, doi: 10.1007/s00382-008-0510-7. 16

Liu, W. T., Tang, W., Polito, P. S., 1998. Nasa scatterometer provides global ocean-surface wind fields with more structures than numerical weather prediction. Geophys. Res. Lett. 24, 761-764. 10

Lucas, M., Ayoub, N., Barnier, B., Penduff, T., de Mey, P., 2008. Stochastic study of the temperature response of the upper ocean to uncertainties in the atmospheric forcing in an Atlantic OGCM. Ocean Modelling 20, 90-113. 3

Lumpkin, R., Speer, K., 2007. Global ocean meridional overturning. J. Phys. Oceanogr. 37, 2550-2562. 13

Macdonald, A. M., Wunsch, C., 1996. An estimate of global ocean circulation and heat fluxes. Nature 382, 436-439. 18

Madec, G., 2008. NEMO, the Ocean Engine. Tech. rep., Notes de l'IPSL (27), ISSN 1288-1619, Université P. et M. Curie, B102 T15-E5, 4 place Jussieu, Paris cedex 5, 193 pp. 2, 12

Madec, G., Delecluse, P., Imbard, M., Levy, C., 1998. OPA 8.1 general circulation model reference manual. Tech. rep., Notes de l'IPSL, Université P. et M. Curie, B102 T15-E5, 4 place Jussieu, Paris cedex 5, France, 91 pp. 12

Madec, G., Imbard, M., 1996. A global ocean mesh to overcome the North Pole singularity. Climate Dynamics 12, 381-388. 13

Oki, T., 1999. The global water cycle. Global Energy and Water Cycles, K. A. Browning and R. J. Gurney Edition. Cambridge University Press, pp. 10-29. 4

Renwick, J. A., 2004. Trends in the Southern Hemisphere polar vortex in NCEP and ECMWF reanalyses. Geophys. Res. Lett. 31 (7), L07209. 10

Rigor, I., Colony, R., Martin, S., 2000. Variations in surface air temperature observations in the arctic. J. Climate 13, 896-914. 7, 9

Röske, F., 2006. A global heat and freshwater forcing dataset for ocean models. Ocean Modelling 11, 235-297. 2

Serreze, M., Hurst, C., 2000. Representation of mean arctic precipitation from NCEP-NCAR and ERA reanalyses. J. Climate 13, 182-201. 5

Taylor, P. K. (Ed.), 2000. Intercomparison and validation of ocean-atmosphere energy flux fields - Final report of the Joint WCRP/SCOR Working Group on Air-Sea Fluxes. WCRP-112, WMO/TD-1036, 306 pp. 4 
The DRAKKAR Group, 2007. Eddy-permitting ocean circulation hindcasts of past decades. CLIVAR Exchanges 12, 3. 2, 12, 16

Timmermann, R., Goosse, H., Madec, G., Fichefet, T., Ethe, C., Dulière, V., 2005. On the representation of high latitude processes in the ORCA-LIM global coupled sea ice. Ocean Modelling 8, 175-201. 4, 13

Treguier, A.-M., England, M. H., Rintoul, S. R., Madec, G., Sommer, J. L., Molines, J.-M., 2007. Southern Ocean overturning across streamlines in an eddying simulation of the Antarctic Circumpolar Current. Ocean Science 3, 491-507. 18

Troccoli, A., Kållberg, P., 2004. Precipitation correction in the ERA-40 reanalysis. ERA-40 Project Report Series 13. 5, 11, 26

Uppala, S., Kållberg, P., Hernandez, A., Saarinen, S., Fiorino, M., Li, X., Onogi, K., Sokka, N., Andrae, U., Bechtold, V. D. C., 2004. ERA-40: ECMWF's 45-year reanalysis of the global atmosphere and surface conditions 1957-2002. ECMWF Newsletter 101, 2-21. 5

Uppala, S. M., Kållberg, P. W., Simmons, A. J., Andrae, U., da Costa Bechtold, V., Fiorino, M., Gibson, J. K., Haseler, J., Hernandez, A., Kelly, G. A., Li, X., Onogi, K., Saarinen, S., Sokka, N., Allan, R. P., Andersson, E., Arpe, K., Balmaseda, M. A., Beljaars, A. C. M., van de Berg, L., Bidlot, J., Bormann, N., Caires, S., Chevallier, F., Dethof, A., Dragosavac, M., Fisher, M., Fuentes, M., Hagemann, S., Holm, E., Hoskins, B. J., Isaksen, L., Janssen, P. A. E. M., Jenne, R., McNally, A. P., Mahfouf, J.-F., Morcrette, J.-J., Rayner, N. A., Saunders, R. W., Simon, P., Sterl, A., Trenberth, K. E., Untch, A., Vasiljevic, D., Viterbo, P., Woollen, J., 2005. The ERA-40 re-analysis. Quart. J. Roy. Meteor. Soc. 131, 2961-3012. 2, 8

Xie, P., Arkin, P. A., 1997. Global precipitation: A 17-year monthly analysis based on gauge observations, satellite estimate, and numerical model outputs. Bull Amer. Meteor. Soc. 78, 2539-2558. 5

Yashayaev, I. M., Lazier, J. R. N., Clarke, R. A., 2003. Temperature and salinity in the central Labrador Sea during the 1990s and in the context of the longer-term change. International Council for the Exploration of the Sea (ICES), Marine Science Symposia 219, 32 pp. 13

Zhang, Y. C., Rossow, W. B., Lacis, A. A., Oinas, V., Mishchenko, M. I., 2004. Calculation of radiative fluxes from the surface to top of atmosphere based on ISCCP and other global data sets: Refinements of the radiative transfer model and the input data. J. Geophys. Res. 109, 27 pp. 4, 25, 27 


\begin{tabular}{|l|c|c|c|c|}
\hline Forcing set & $\mathbf{U}_{10}$ & $\theta_{\text {air }} q_{\text {air }}$ & $\operatorname{rad}_{s w} \operatorname{rad}_{w w}$ & Precip \\
\hline \hline LYDS & NCEP $^{c}$ & NCEP $^{c}$ & ISCCP-FD $^{c}$ & GXGXS $^{c}$ \\
\hline LYDS-H1 & ERA40 & NCEP $^{c}$ & $/ /$ & $/ /$ \\
\hline LYDS-H2 & NCEP $^{c}$ & ERA40 & $/ /$ & $/ /$ \\
\hline DFS3 & ERA40 & ERA40 & $/ /$ & $/ /$ \\
\hline DFS3.1 & $/ /$ & ERA40 $^{d}$ & $/ /$ & $/ /$ \\
\hline DFS3.2 & ERA40 $^{d}$ & $/ /$ & $/ /$ & $/ /$ \\
\hline DFS4 & ERA40 $^{d}$ & ERA40 $^{d}$ & ISCCP-FD $^{d}$ & GXGXS $^{d}$ \\
\hline
\end{tabular}

Table 1: Main and intermediate datasets studied. From LYDS to DFS4. The $c$ superscript refers to the corrections applied to original datasets by Large and Yeager (2004), while $d$ refers to the corrections proposed in this paper. ISCCP-FD, the radiation product of Zhang et al. (2004) is discussed in Section 3.1.1 GXGXS, the hybrid precipitation product of Large and Yeager (2004) is discussed in Section 3.1 .2

\begin{tabular}{|ll|c|c|c|c|c|}
\hline & & LYDS & DFS3 & DFS3.1 & DFS3.2 & DFS4 \\
\hline \hline$Q_{\text {net }}^{\text {SSTobs. }}$ & $\left(\mathrm{W} / \mathrm{m}^{2}\right)$ & +10.4 & +12.8 & +13.5 & +1.1 & +0.3 \\
\hline$Q_{\text {net }}^{\text {ORCA2 }}$ & $\left(\mathrm{W} / \mathrm{m}^{2}\right)$ & +0.9 & 0 & 0 & +0.3 & +0.4 \\
\hline \hline$F_{w}^{S S T o b s .}$ & $(\mathrm{mm} /$ year $)$ & +25 & +56 & +54 & -86 & -0.2 \\
\hline$F_{w}^{O R C A 2}$ & $(\mathrm{~mm} /$ year $)$ & +4 & +7 & +8 & -4 & +0.6 \\
\hline
\end{tabular}

Table 2: Mean global imbalances of heat and freshwater, for the period 1958-2004, as computed by the prescribed SST approach (Section 2) and by the ORCA2 model (using SST computed by the model). 
(a)

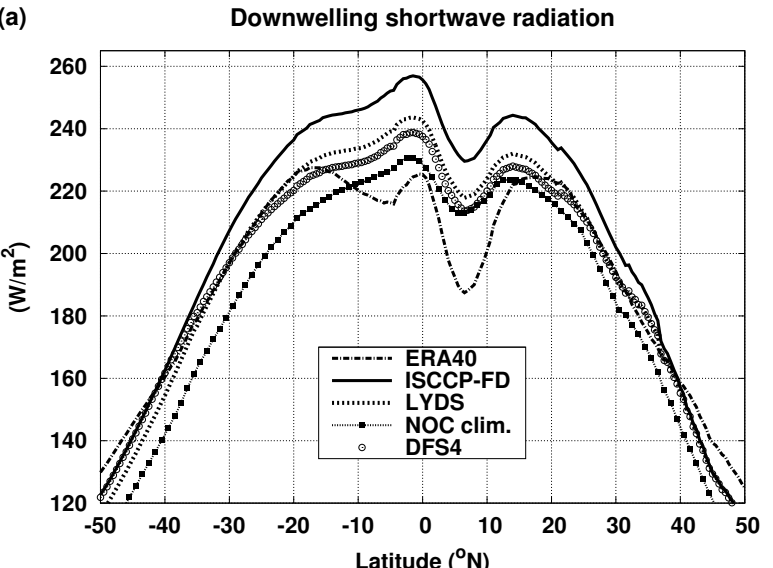

(b)

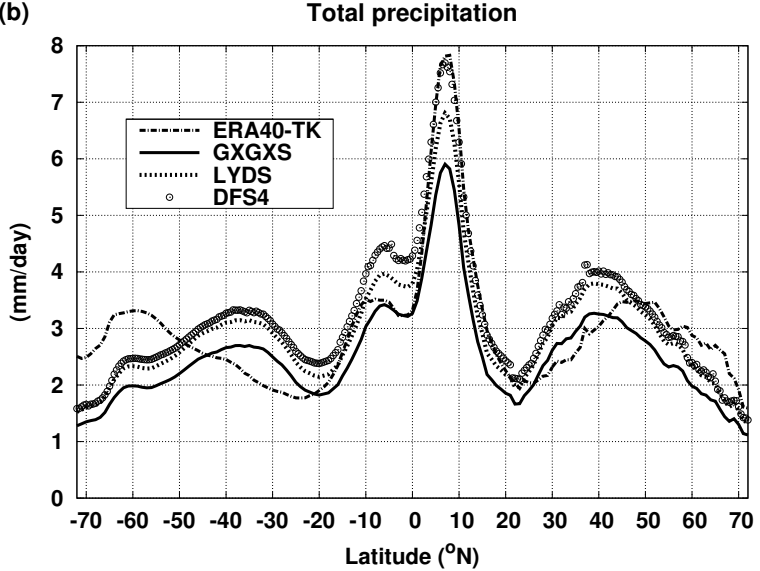

Figure 1: (a) Zonally-averaged downwelling shortwave radiation over sea (1984-2001); DFS4 radiation product is discussed in Section 4 (b) zonally-averaged total precipitation over sea (1979-2001), including corrected ERA40 precipitation (Troccoli and Kållberg, 2004). 


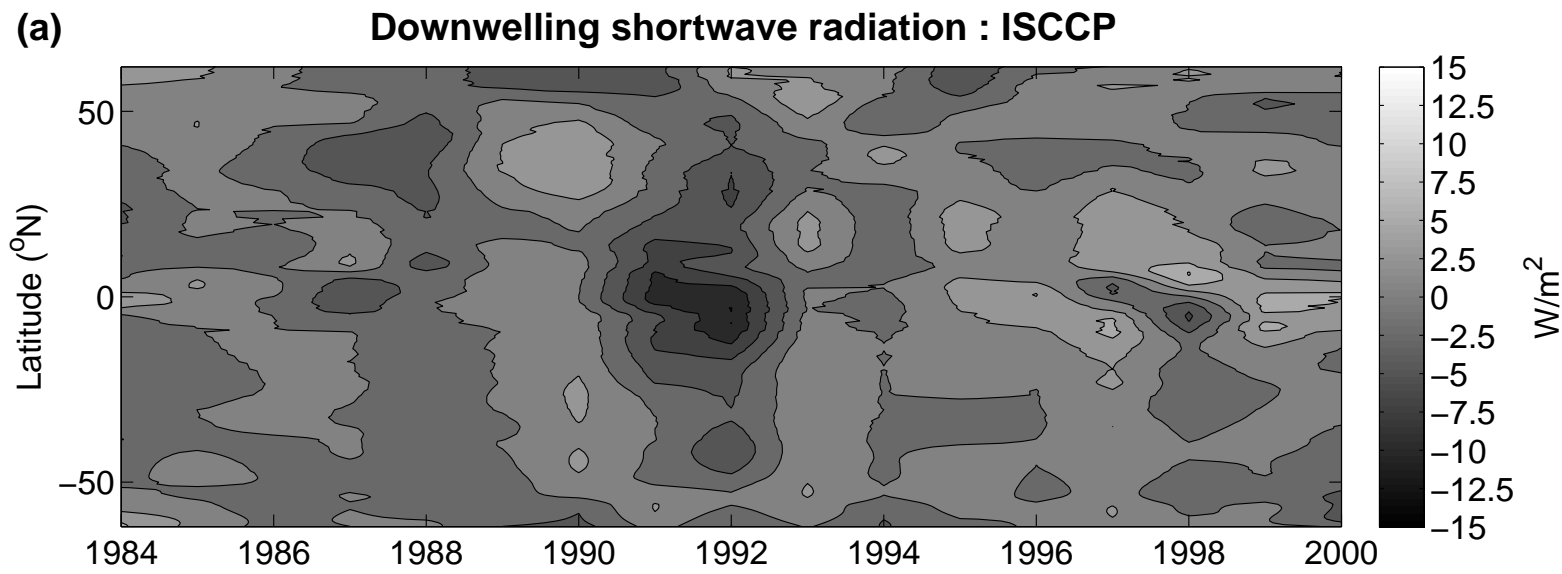

(b) Downwelling shortwave radiation : ERA40

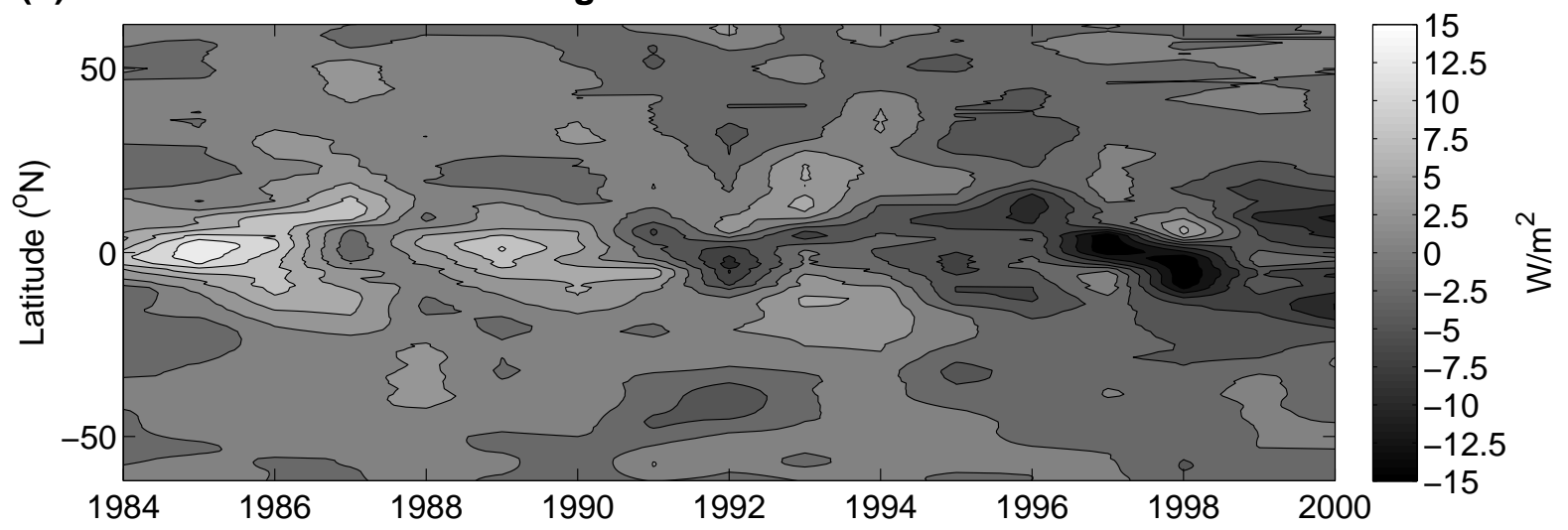

Figure 2: Time-latitude Hovmöller diagram of the annual zonally-averaged anomaly of downwelling shortwave radiation over sea: (a) ISCCP-FD (Zhang et al., 2004), (b) ERA40. 

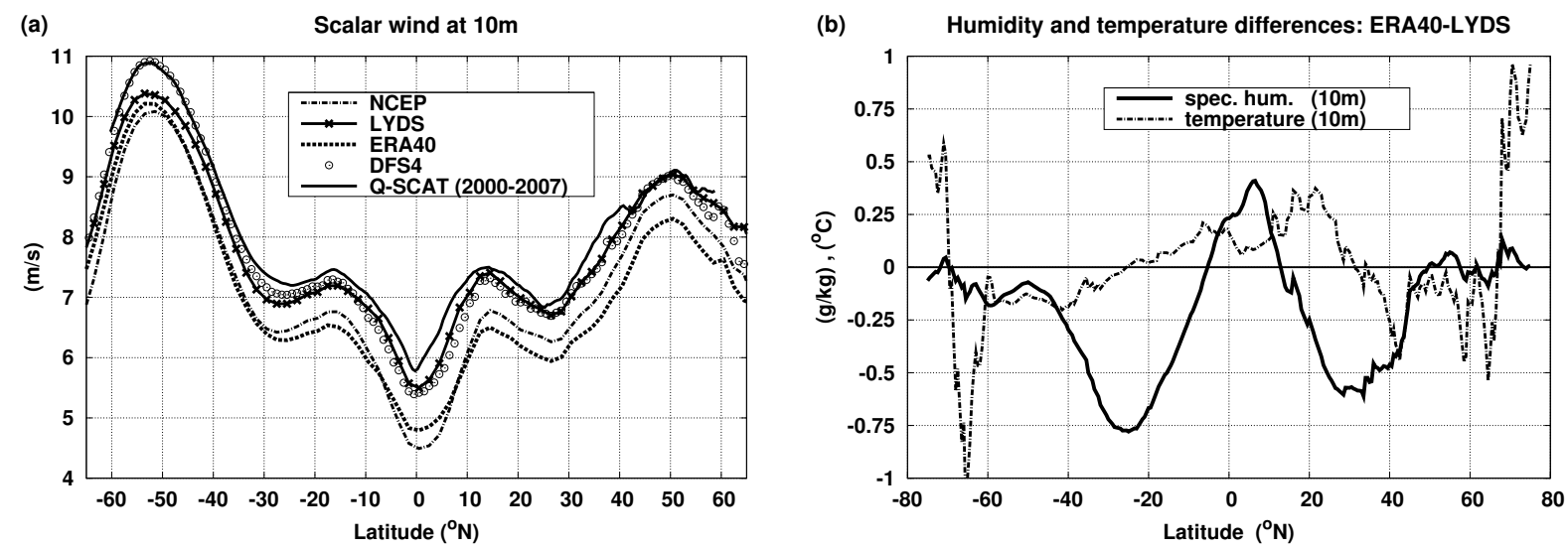

Figure 3: (a) Zonally-averaged wind speed at $10 \mathrm{~m}$ over sea from various origins (1958-2001, except for QuikSCAT), DFS4 is discussed in Section 4, (b) zonally-averaged difference of air specific humidity and temperature at 10 m over sea between ERA40 and LYDS (1984-2001). 
(a) q10: ERA40-LYDS (Winter, DJF)

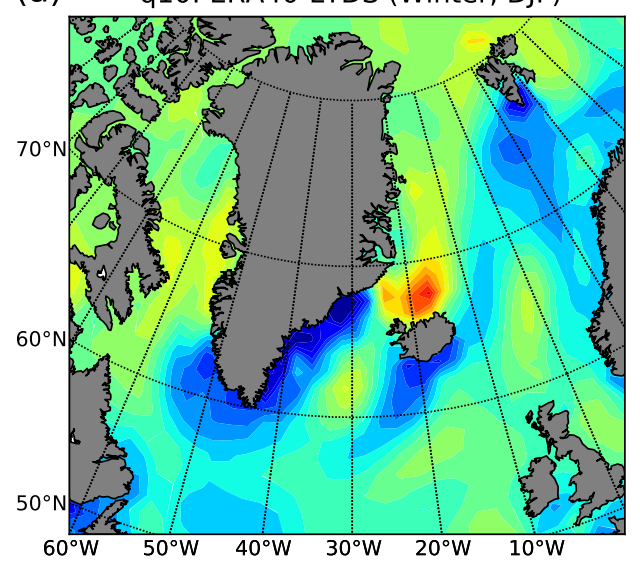

(c)

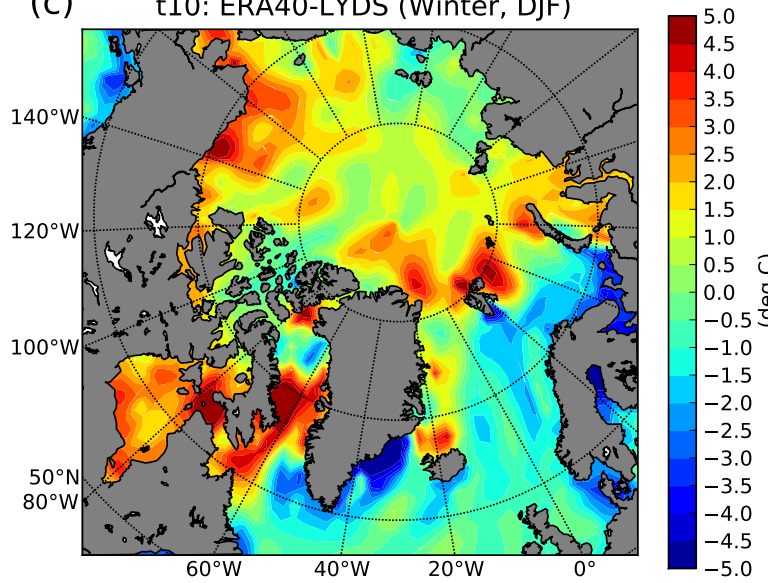

(b) q10: ERA40-LYDS (Summer, JJA)

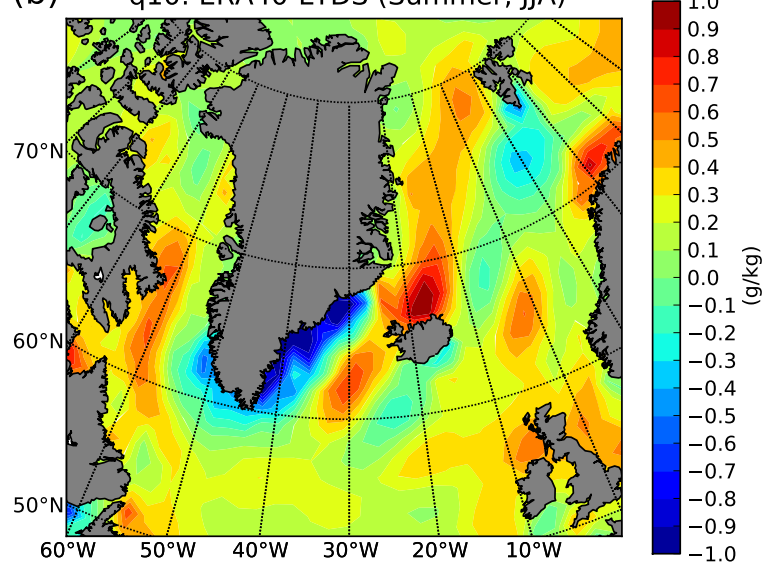

(d)

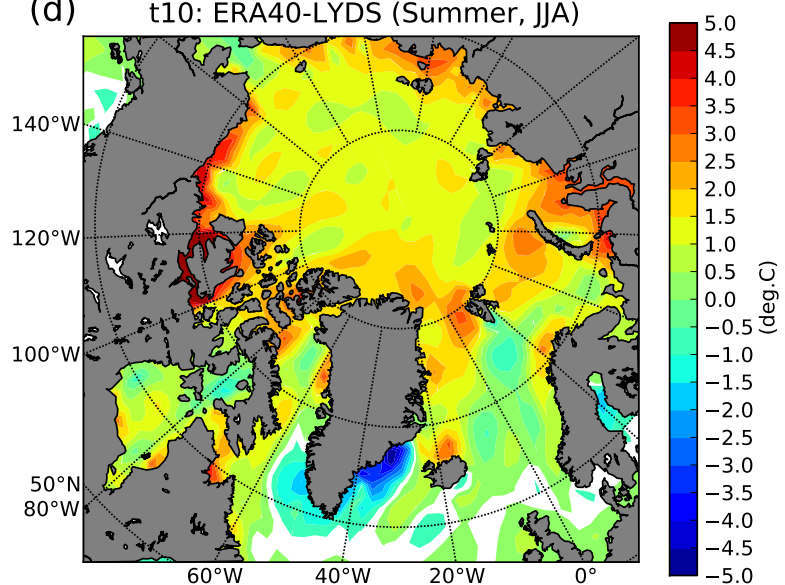

Figure 4: Seasonal comparison of mean air specific humidity and temperature at $10 \mathrm{~m}$ between ERA40 and LYDS in the nordic seas (1984-2001), $(a, c)$ winter and (b,d) summer. 

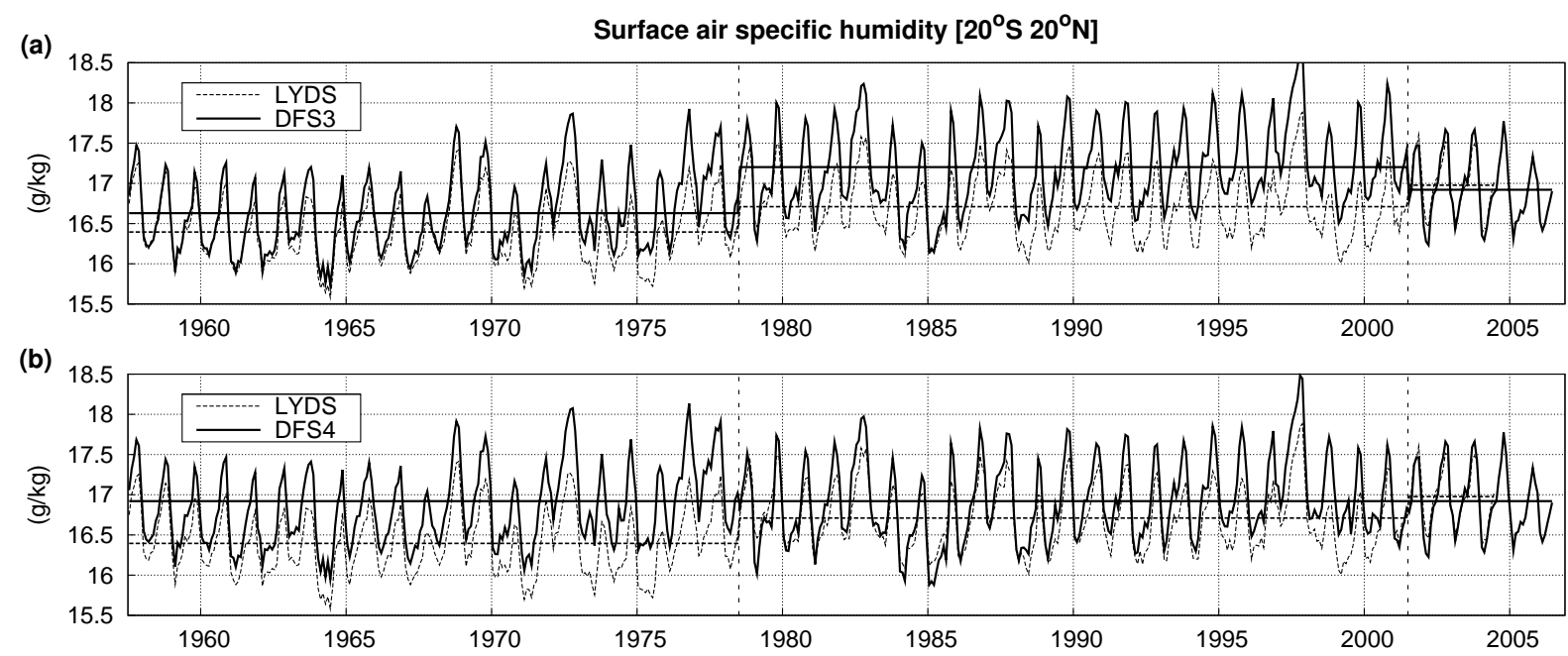

Figure 5: Mean monthly tropical specific humidity (spatially-averaged between $20^{\circ} \mathrm{S}$ and $20^{\circ} \mathrm{N}$ ) and its mean value for each of the 3 periods 1958-1978, 1979-2001 and 2002-2006; (a) LYDS and DFS3, (b) LYDS and DFS4 (DFS3 corrected).
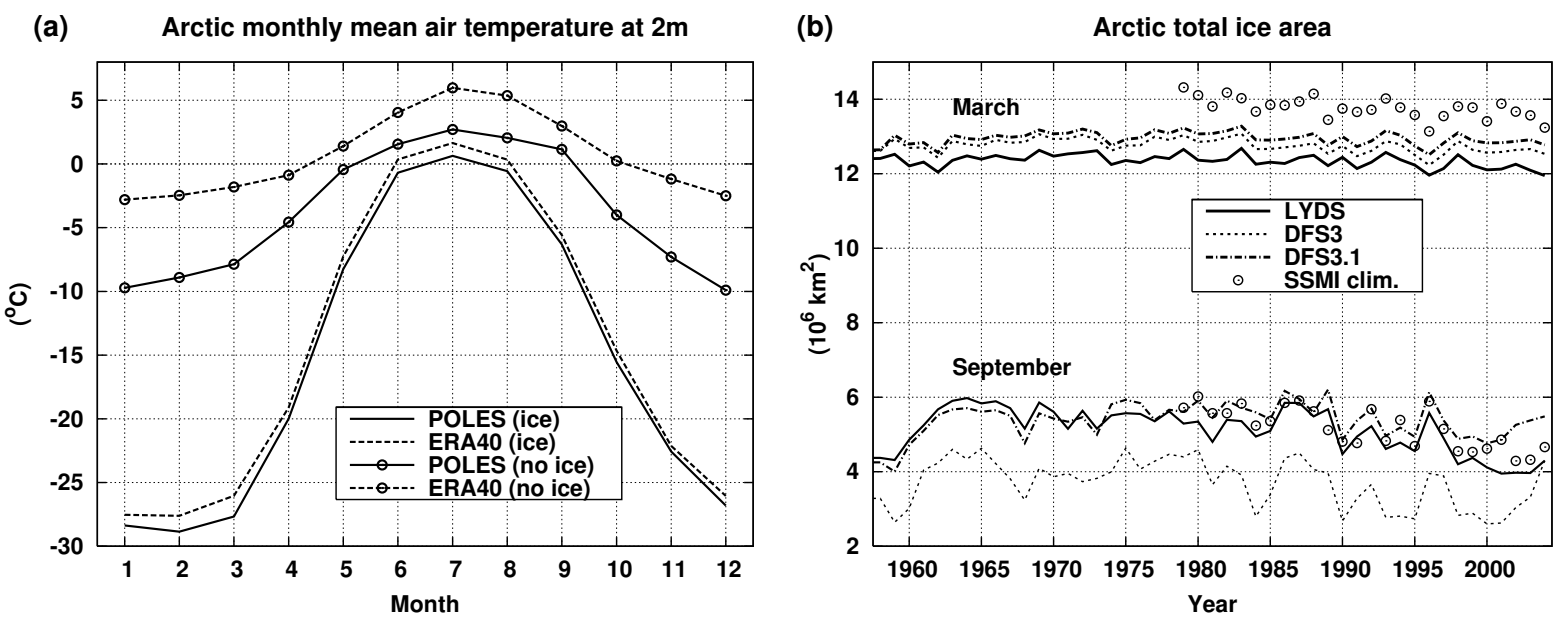

Figure 6: (a) Climatological (1979-1997) seasonal cycle of monthly air temperature (at $2 \mathrm{~m}$ ) over the Arctic north of $70^{\circ} \mathrm{N}$ from POLES and ERA40, depending on the presence of sea-ice or not (using a climatological sea-ice mask from the SSM/I). (b) March (thick lines) and September (thin lines) Arctic sea-ice extent from the ORCA2 model versus SSM/I observations. 
(a)

Wind speed at $10 \mathrm{~m}\left[65^{\circ} \mathrm{S} 50^{\circ} \mathrm{S}\right]$

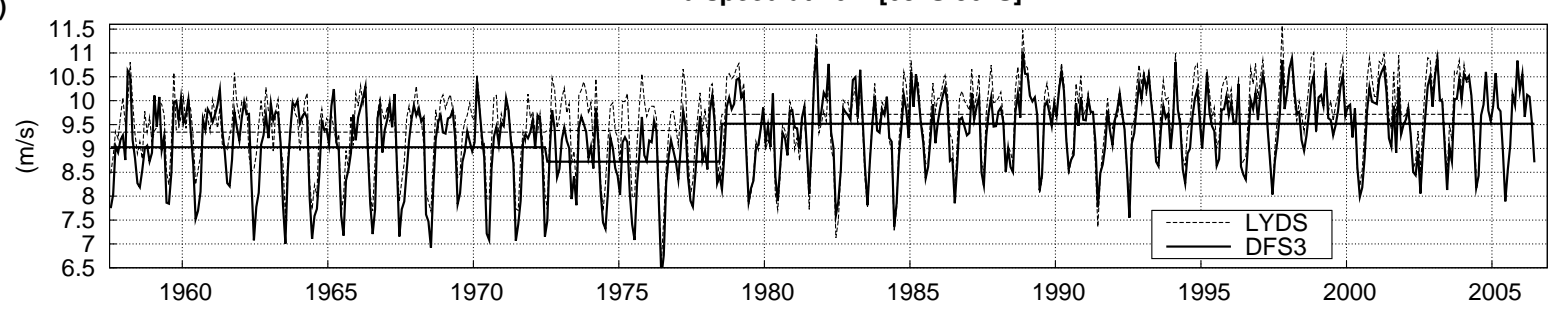

(b)

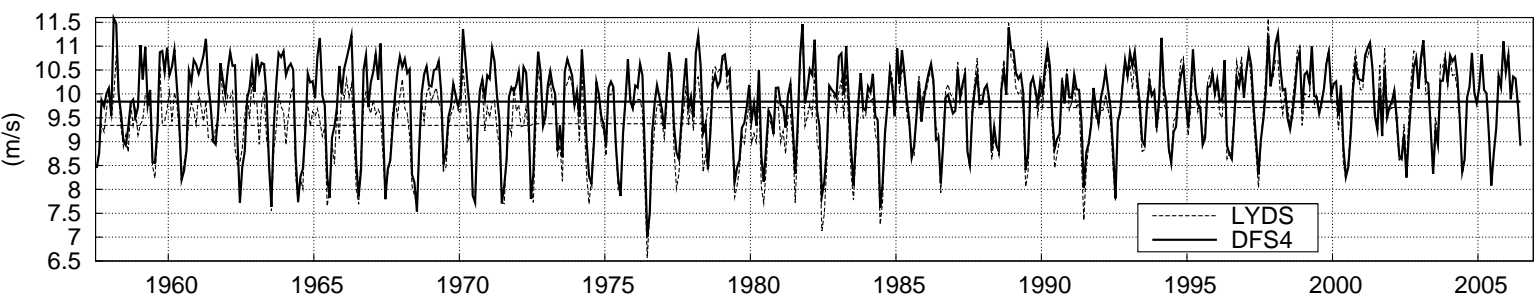

Figure 7: Mean monthly wind speed in mid-high southern latitudes (spatially-averaged between $50^{\circ} \mathrm{S}$ and $65^{\circ} \mathrm{S}$ ) and its mean value for each of the 4 periods 1958-1972, 1973-1978, 1979-2001 and 2002-2006; (a) LYDS and DFS3, (b) LYDS and DFS4 (DFS3 corrected).
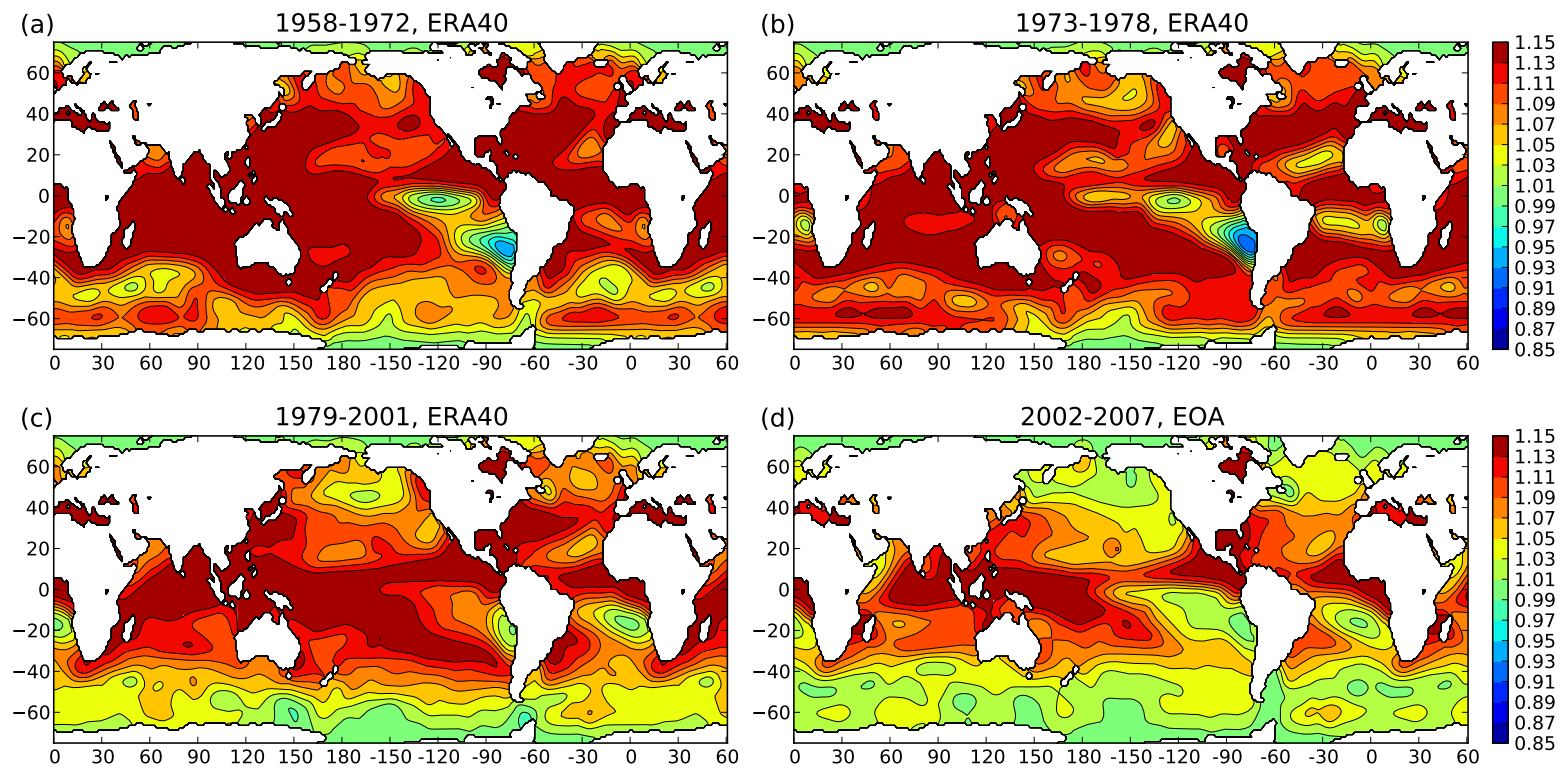

Figure 8: Factor maps applied to DFS3 wind to correct both components of the wind vector at $10 \mathrm{~m}$, for the four relevant periods. 


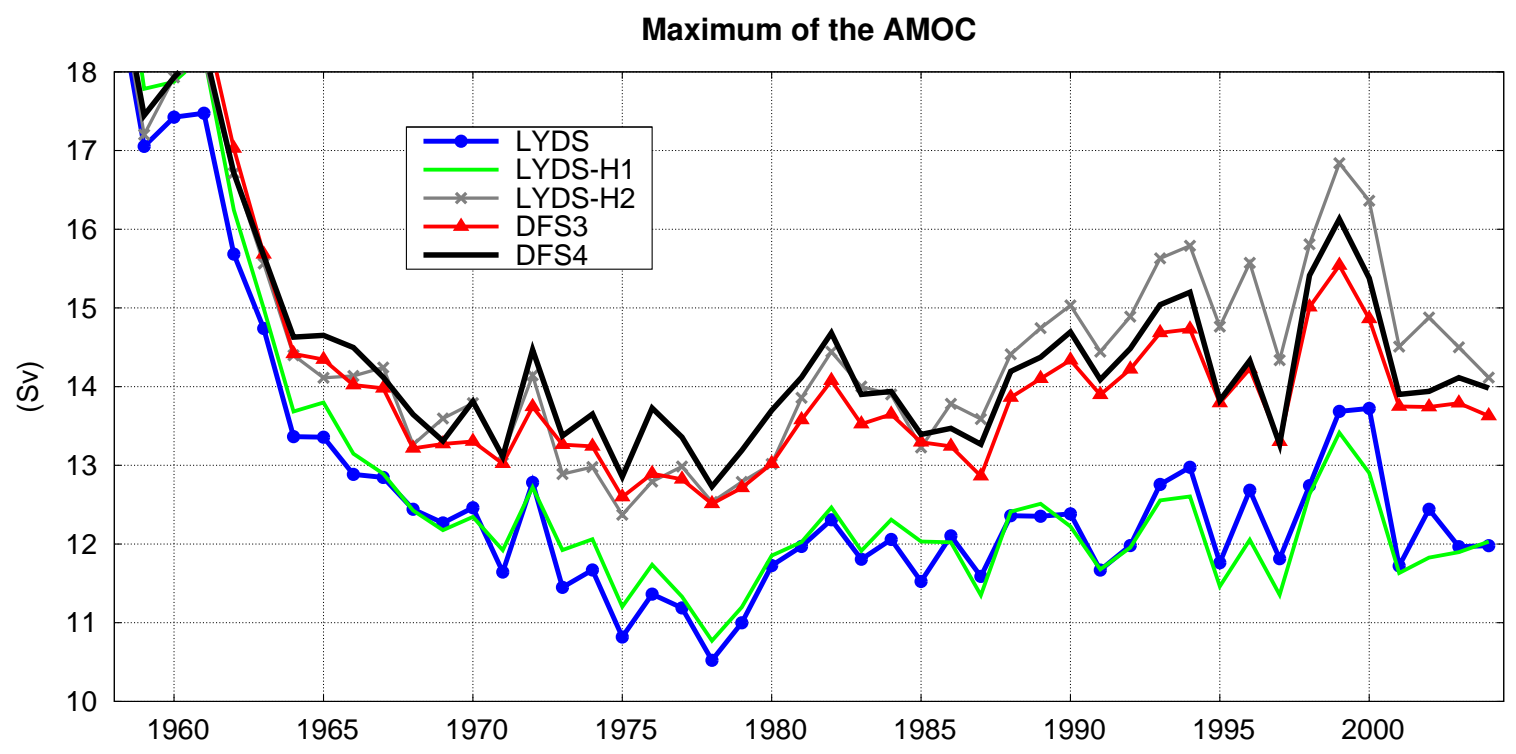

Figure 9: Maximum value of the mean annual Atlantic meridional overturning circulation (AMOC, calculated as the maximum of the meridional latitude-depth overturning stream function between $20^{\circ} \mathrm{N}$ and $60^{\circ} \mathrm{N}$, and $200 \mathrm{~m}$ and $2500 \mathrm{~m}$ ).
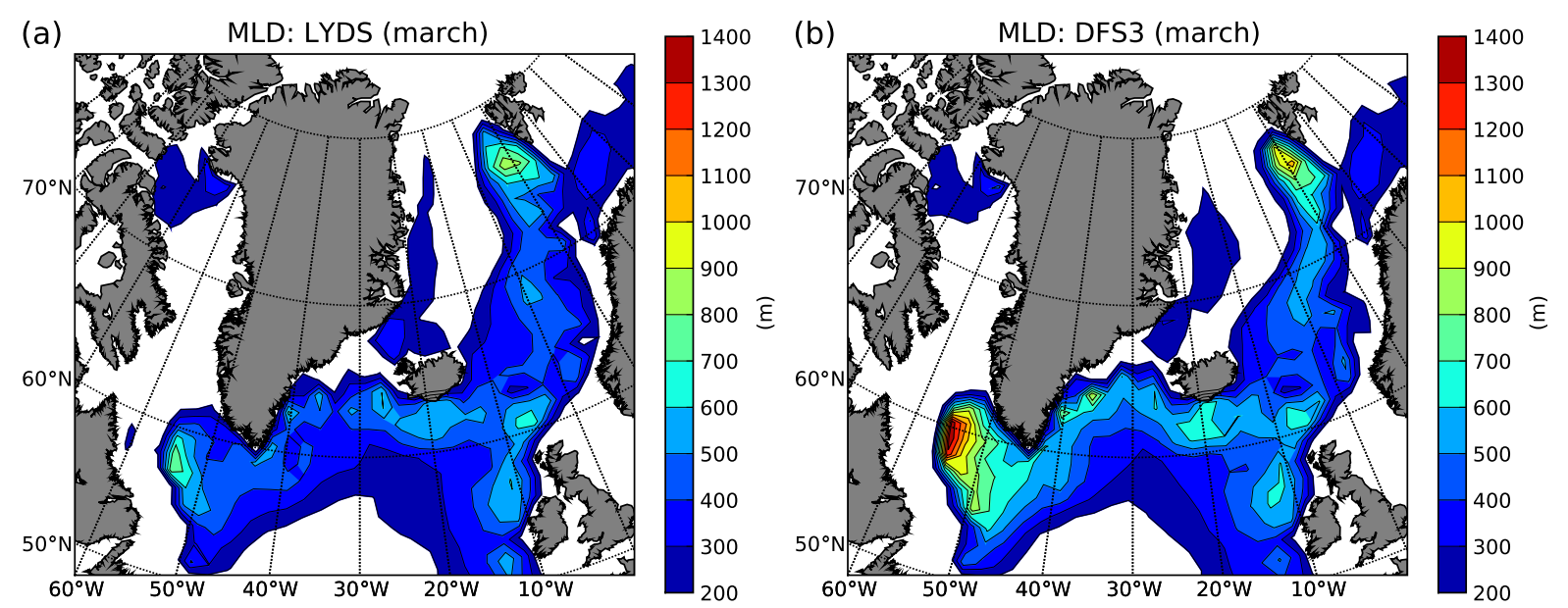

Figure 10: Mean mixed layer depth in march (1984-2004) as computed by the ORCA2 model forced by two different forcing sets: (a) LYDS, (b) DFS3. 
(a)

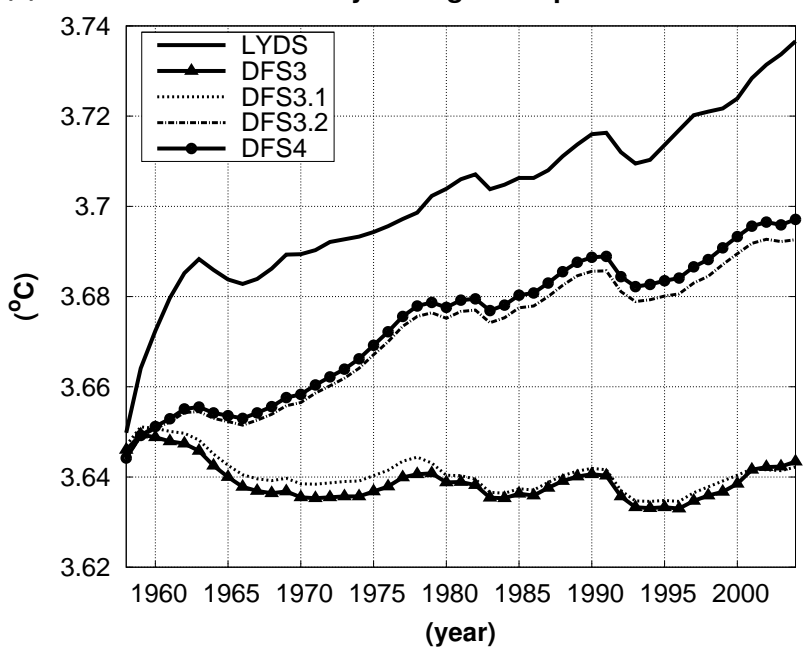

(c)

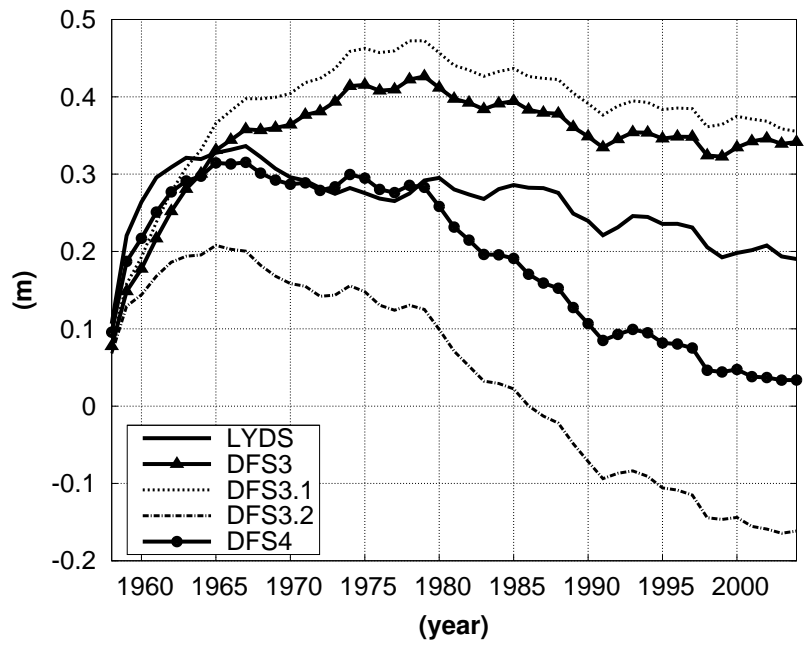

(b)

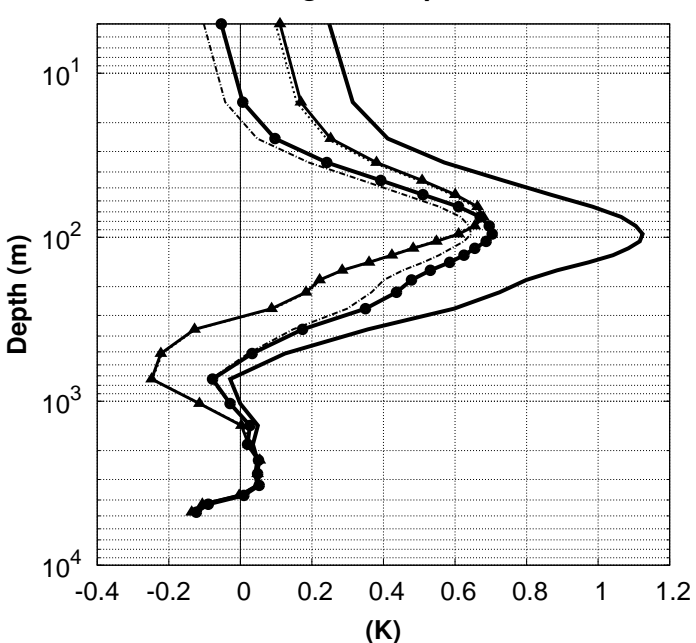

(d)

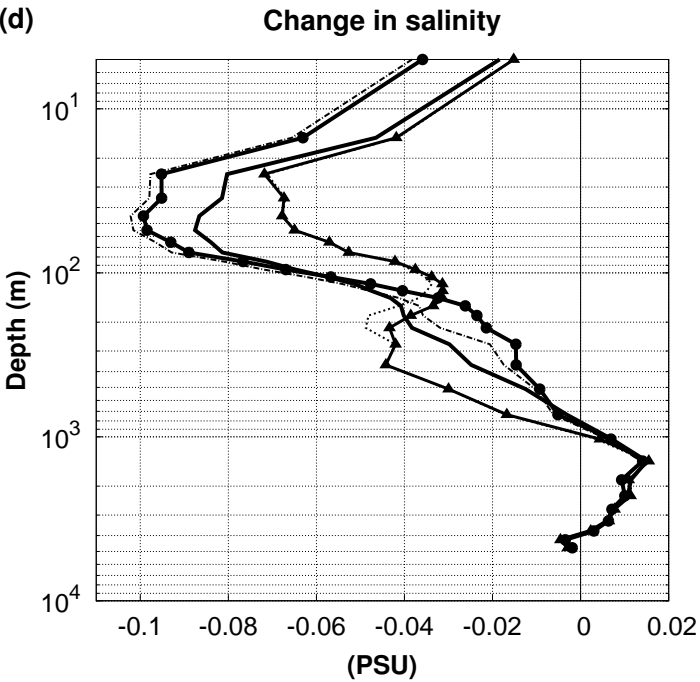

Figure 11: Global oceanic volume-averaged evolution of (a) temperature and (c) SSH computed by the ORCA2 model. Global oceanic level-averaged drift of (b) temperature and (d) salinity as a function of depth after 47 years of simulation, equivalent to comparing the last year to the initial condition (Levitus, 1998). The vertical patterns of the drift in (b) and (d) appear early in the run and are rapidly steady, so the plots are representative. In (b) and (d), the curves for DFS3 and DFS3.1 are almost identical. 

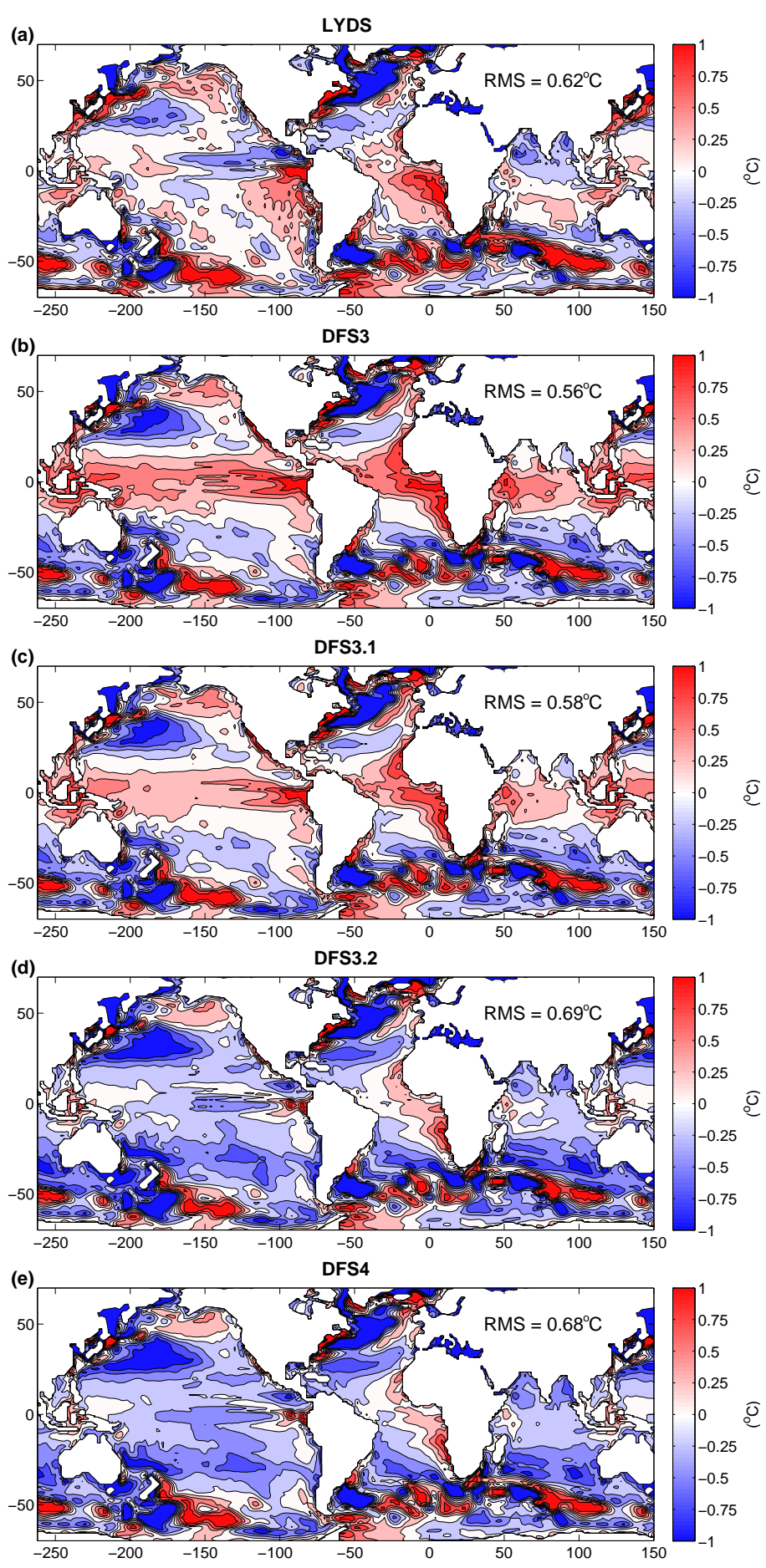

Figure 12: Mean (1984-2004) surface temperature difference between the model SST and the SST climatology of Hurrell et al. (2008). For each map, the corresponding global RMS value calculated from monthly-averaged SST time series (model versus interannual Hurrell climatology) between 1984 and 2004 is given. It is calculated on a global domain covering latitudes from $-55^{\circ} \mathrm{N}$ to $+60^{\circ} \mathrm{N}$ that excludes the Mediterranean Sea. 


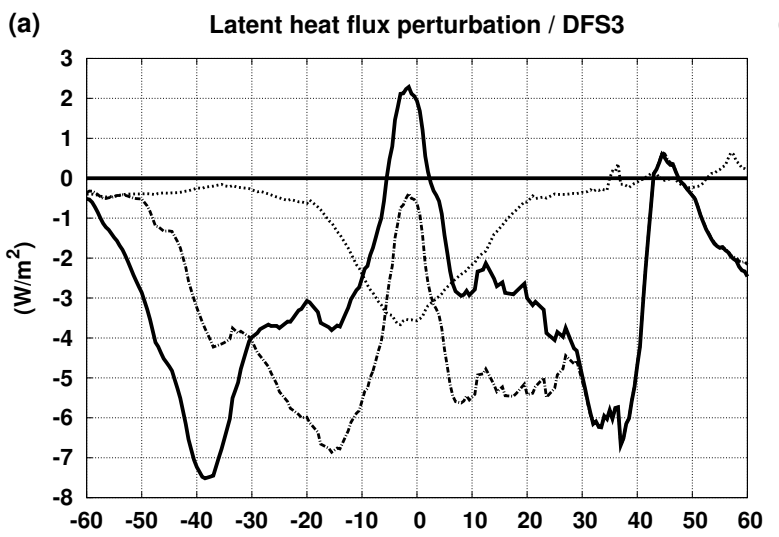

(b) Sensible heat flux perturbation / DFS3
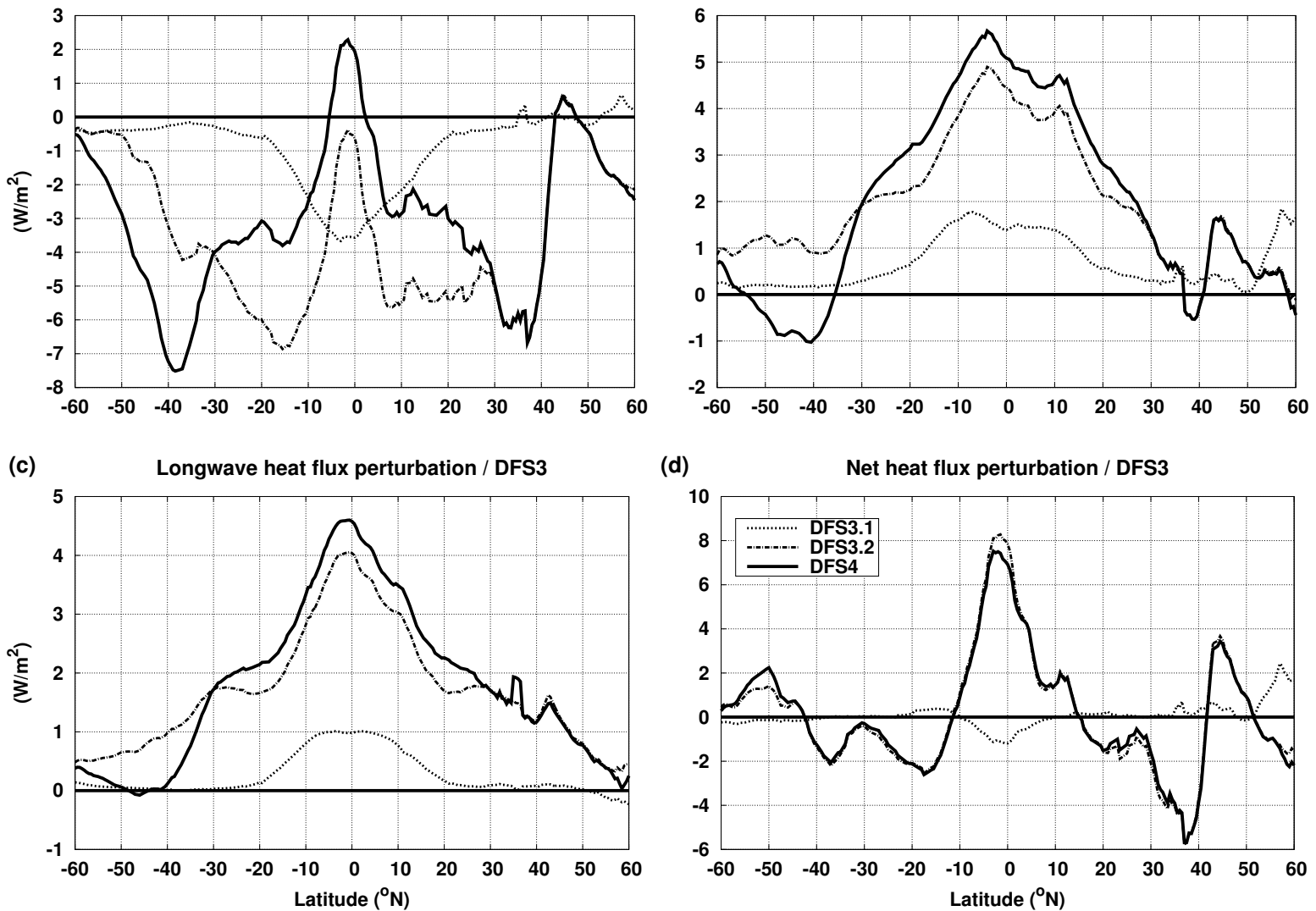

(d)

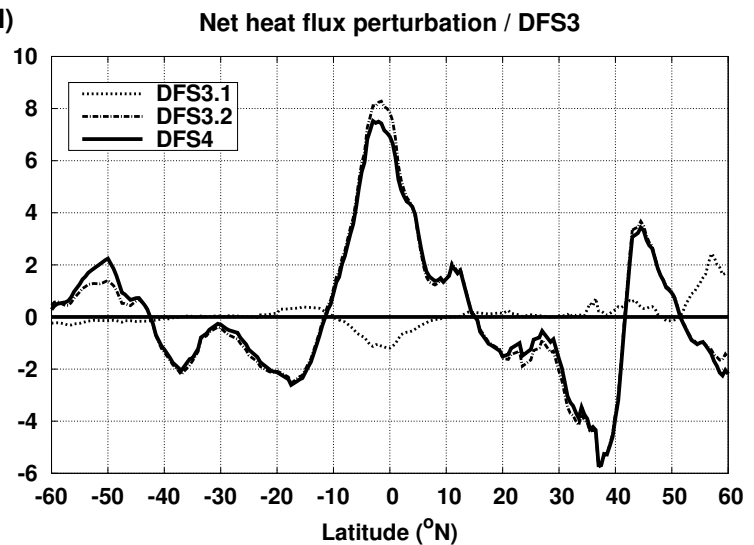

Figure 13: Impact of the various corrections applied to the atmospheric forcing variables on the zonal average of the model mean latent heat flux (a), sensible heat flux (b), longwave radiation (c), and net heat flux (d), (1984-2004). Differences relative to DFS3 fluxes are plotted for simulations DFS3.1 (air temperature and humidity correction), DFS3.2 (air temperature and humidity correction + wind correction), and DFS4 (air temperature and humidity correction + wind correction + radiation correction). Since the zonal mean of the 3 first heat flux components is negative, positive/negative values indicates that the correction induces a gain/loss of heat for the ocean with regards to the DFS3 forcing. 

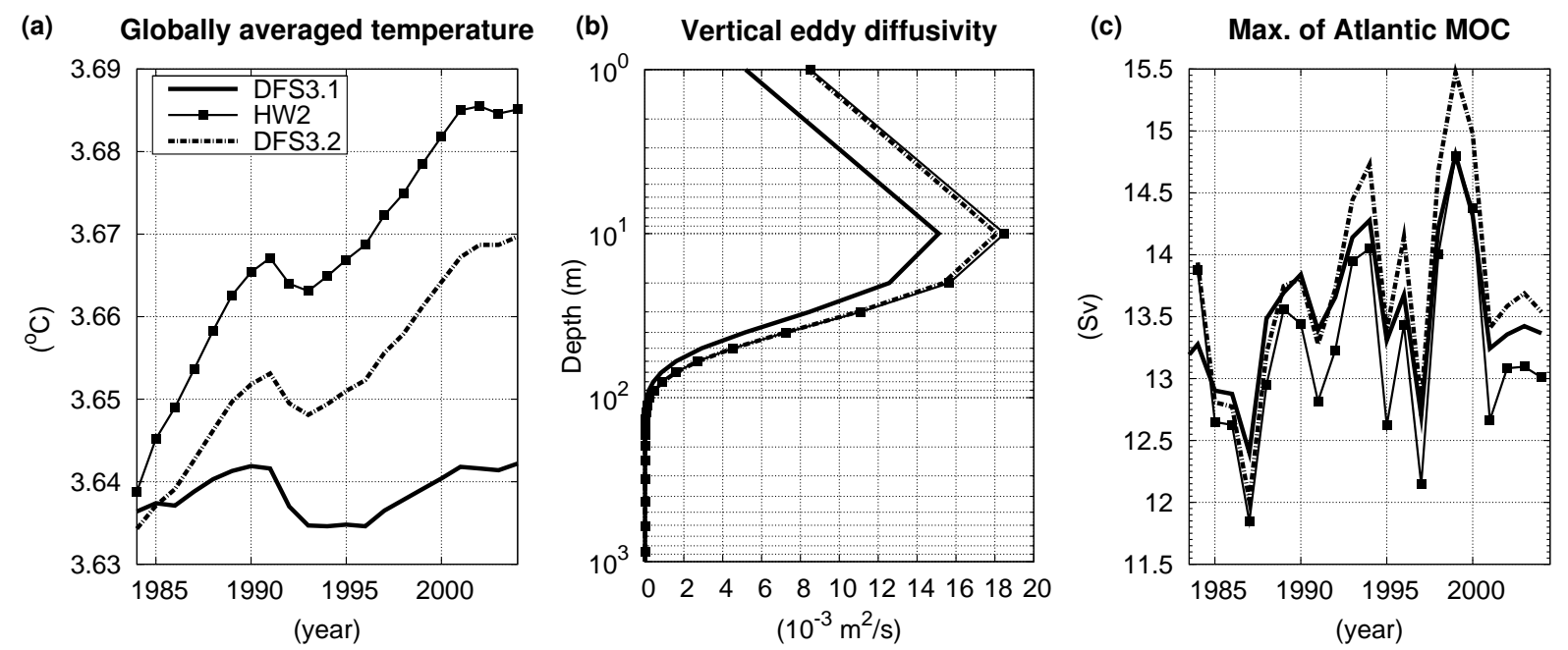

Figure 14: Sensitivity to the mechanical forcing. (a) Evolution of the global oceanic volume-averaged temperature, (b) level-averaged vertical eddy diffusivity in the tropical western Pacific Ocean (between $156^{\circ} \mathrm{E}-146^{\circ} \mathrm{W}$ and $8^{\circ} \mathrm{S}-8^{\circ} \mathrm{N}$ ) (1984-2004), (c) evolution of the maximum of the AMOC (as described in Fig. (9). The base run is DFS3.1. In run HW2, ERA40 rescaled winds are only used to compute the wind stress, the turbulent heat fluxes are computed with ERA40 uncorrected winds. Note that for these diagnostics both HW2 and DFS3.2 runs were started in 1984 with DFS3.1 ocean state, so that the three runs share the same initial condition in 1984. 

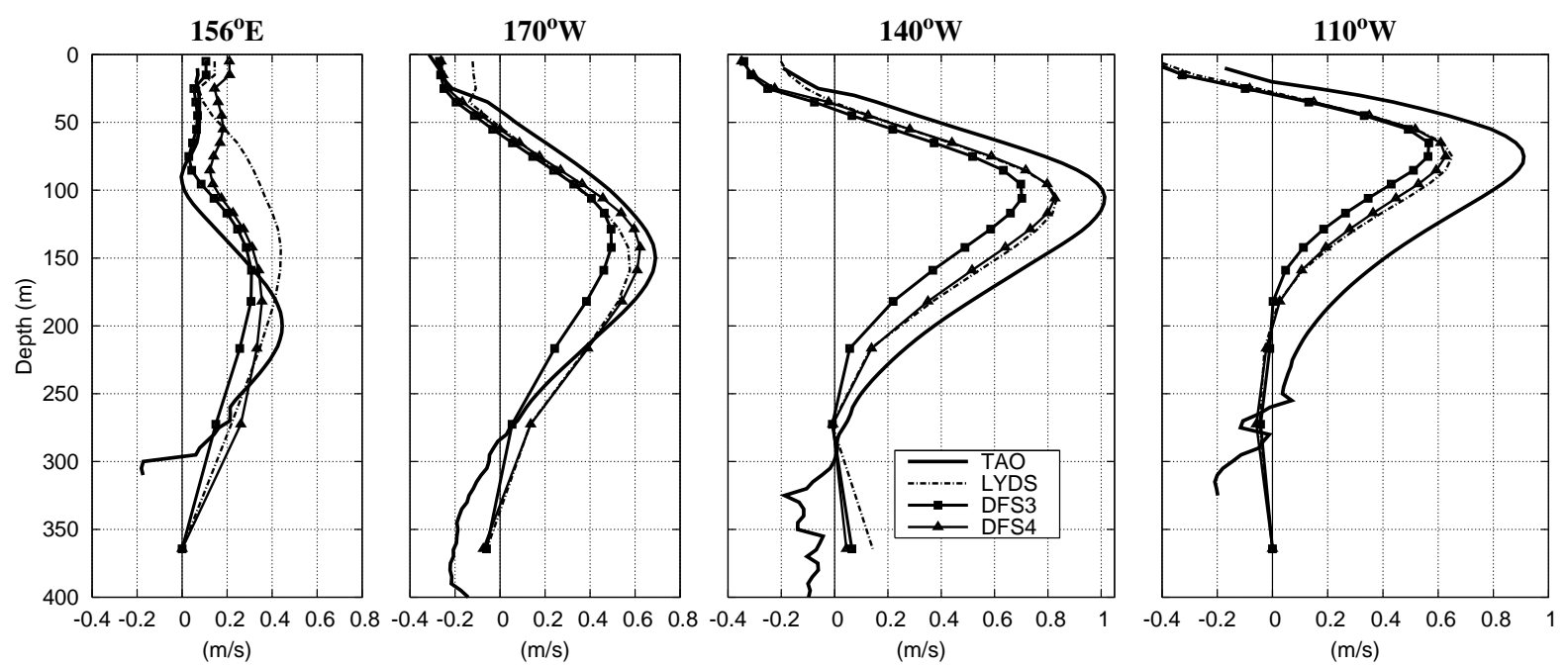

Figure 15: Comparison of mean equatorial under current profiles between ORCA2 simulations and TAO mooring data for different longitudes (1992-2001), using exact collocation in space and time of the model and TAO data. 